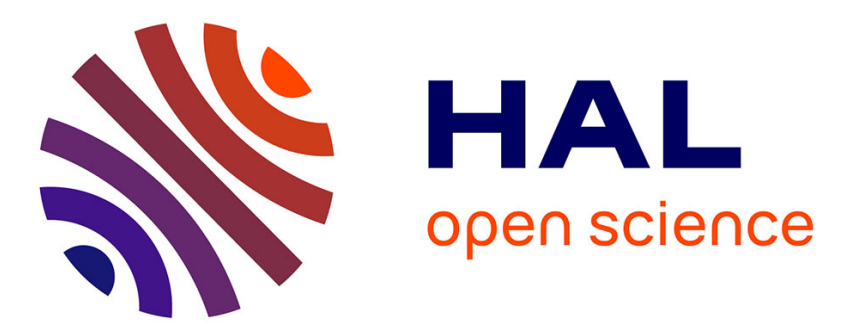

\title{
Frequency-dependent modulation of glycine receptor activation recorded from the zebrafish larvae hindbrain
}

J.M. Rigo, P. Legendre

\section{To cite this version:}

J.M. Rigo, P. Legendre. Frequency-dependent modulation of glycine receptor activation recorded from the zebrafish larvae hindbrain. Neuroscience, 2006, 140, pp.389-402. 10.1016/j.neuroscience.2006.01.057 . hal-00086009

\section{HAL Id: hal-00086009 https://hal.science/hal-00086009}

Submitted on 19 Jul 2006

HAL is a multi-disciplinary open access archive for the deposit and dissemination of scientific research documents, whether they are published or not. The documents may come from teaching and research institutions in France or abroad, or from public or private research centers.
L'archive ouverte pluridisciplinaire HAL, est destinée au dépôt et à la diffusion de documents scientifiques de niveau recherche, publiés ou non, émanant des établissements d'enseignement et de recherche français ou étrangers, des laboratoires publics ou privés. 
Cellular Neuroscience: Dr. M. Segal

\section{Frequency-dependent modulation of glycine receptor activation recorded from the zebrafish Larvae hindbrain}

Jean-Michel RIGO ${ }^{2,3}$ and Pascal LEGENDRE ${ }^{1}$

${ }^{1}$ UMR 7102, Université Paris 6, bâtiment B, 6eme étage, case 1, 7 quai St Bernard, F75252 Paris cedex 05, France.

${ }^{2}$ Hasselt University, BIOMED Research Institute, Agoralaan, Gebouw D, B-3590 Diepenbeek, Belgium.

${ }^{3}$ Université de Liège, CNCM, Sart-Tilman, B-4000 Liège, Belgium

\section{Corresponding author}

Pascal LEGENDRE, UMR 7102 Neurobiologie des Processus Adaptatifs, Laboratoire Dynamique de la Synapse, Bât B 6ème étage, case 1, Université Pierre et Marie Curie, 7 Quai Saint Bernard, 75252 Paris Cedex 05, France, telephone: +33 1442725 19, fax: +33 14427 27 81, e-mail: pascal.legendre@snv.jussieu.fr

\section{Keywords}

Glycine receptors, patch-clamp, desensitization, frequency, synaptic activity, modulation

\section{Nonstandard abbreviations}

$\mathrm{GABA}_{\mathrm{A}} \mathrm{R}$ : type $\mathrm{A} \gamma$-aminobutyric acid receptor; GlyR: glycine receptor, M-cell : Mauthner cell

\section{ACKNOWLEDGEMENTS}

We thank Dr R Miles for reviewing the manuscript. This work was supported by INSERM (France), the Fondation pour la Recherche Médicale (FRM, France), Association Française contre les Myopathies, the Centre National de la Recherche Scientifique (CNRS, France) and INSERM - CFB agreement (P. Legendre and J.M. Rigo). 


\section{ABSTRACT}

In vertebrates, most glycinergic inhibitory neurons discharge phasically at a relatively low frequency. Such a pattern of glycine liberation from presynaptic terminals may affect the kinetics of post-synaptic glycine receptors. To examine this influence, we have analyzed the behavior of glycine receptors in response to repetitive stimulation at frequencies at which consecutive outside-out current did not superimpose $(0,5-4 \mathrm{~Hz})$. Neurotransmitter release was mimicked on outside-out patches from zebrafish hindbrain Mauthner cells using fast flow application techniques. The amplitude of outside-out currents evoked by short (1 ms) repetitive applications of a saturating concentration $(3 \mathrm{mM})$ of glycine remained unchanged for application frequencies $\leq 1 \mathrm{~Hz}$. When the application frequency was increased from 1 to $4 \mathrm{~Hz}$, the amplitude of the outside-out currents decreased with time to reach a steady state level. This decrease in current amplitude was larger and occurred faster with increasing application frequencies. Recovery occurred when the stimulation frequency was decreased back to $1 \mathrm{~Hz}$. The recovery time constant was independent on the application frequency. This frequency-dependent inhibition was also observed for non-saturating glycine concentrations. Our results indicate that glycine receptor activity is down regulated when the stimulation frequency increases to values $>1 \mathrm{~Hz}$. Glycine-evoked current simulations using a simple Markov model describing zebrafish glyR kinetic behavior, indicates that this down regulation of glycine receptor efficacy is due to a progressive accumulation of the receptors in a long lasting desensitization state. Our simulations suggest that this down regulation can occur even when spontaneous inhibitory currents were generated randomly at a frequency $>1 \mathrm{~Hz}$. 


\section{INTRODUCTION}

Glycine is one of the most important inhibitory neurotransmitter in the spinal cord and brainstem of various species. The glycine receptor (GlyR) is an ionotropic receptor permeable to anions. Four $\alpha$ subunits $(\alpha 1, \alpha 2, \alpha 3, \alpha 4)$ and one $\beta$ glycine receptor subunit have been described (see for review (Legendre, 2001)), the $\beta$ subunit bearing the binding site for the anchoring protein gephyrin (Meyer et al., 1995) while the $\alpha$ subunits contain the agonist binding sites. In the adult brainstem and spinal cord, it is now widely accepted that GlyRs mainly consist of $\alpha 1 / \beta$ heteropentamers with $2 \alpha 1$ subunits and $3 \beta$, as recently described (Grudzinska et al., 2005). GlyRs are functionally identical in mammals and in the zebrafish (see for review (Legendre, 2001)).

In the zebrafish hindbrain the variability in miniature inhibitory post-synaptic currents (mIPSC) amplitudes has been shown to be complex, depending both on the variation in the number of postsynaptic GlyRs per synapse, although postsynaptic GlyRs are not saturated after the release of a vesicle (Suwa et al., 2001; Rigo et al., 2003), and on variation in the number of neurotransmitter molecules released per vesicle (Rigo et al., 2003). Another source of mIPSC amplitude fluctuation, even at low release frequencies, may arise from a short-term adaptation of synaptic efficacy as a consequence of intrinsic receptor kinetic characteristics.

Short-term plasticity, either facilitation or depression, is a common feature at fast synapses in Vertebrates which permits adaptation of synaptic responses during repetitive stimulation. At inhibitory synapses, short-term facilitation, short-term depression and pairedpulse depression have been described for GABA-mediated neurotransmission (Donato \& Nistri, 2001; Kirischuk et al., 2002). Short-term depression at GABAergic synapses can result from a fast accumulation of postsynaptic receptors in a desensitized state (Jones \& Westbrook, 1995). This leads to a prolongation of GABAergic responses by maintaining the receptors in a liganded closed state from which they can reopen (Jones \& Westbrook, 1995). 
Less is known about short-term plasticity at glycinergic synapses. GlyRs desensitize slowly and, accordingly, currents evoked by short glycine pulses $(1 \mathrm{~ms})$ show little or no paired-pulse inhibition (Legendre, 1998; Singer \& Berger, 1999). Similarly, slow desensitization does not modify the time course of glycinergic postsynaptic responses (Legendre, 1998; Singer \& Berger, 1999) and it has been suggested that this slow desensitization process can control synaptic strength by decreasing glycinergic synaptic response amplitude during epileptic-like presynaptic high frequency firing only (Gentet \& Clements, 2002). In vertebrates, most glycinergic inhibitory neurons display at rest a phasic activity pattern at a relatively low frequency (Krupp et al. 1997 ; Jeong et al. 2003, Pagnotta et al. 2005), which is subject to presynaptic modulation (Jeong et al. 2003, Pagnotta et al. 2005) The slow desensitization of GlyRs (Legendre 1998; Hartis and Manis 1998) might modulate the amplitude of sequential glycinergic responses even during repetitive firing at low frequency. This would occur if a small fraction of postsynaptic receptors accumulate in a desensitized state when activated at a frequency close to the recovery rate constant from the desensitized state. Nevertheless, relations between GlyR kinetics and repetitive firing at a frequency at which postsynaptic responses rarely superimpose have not yet been analysed.

To investigate this possibility, we have analyzed the behavior of GlyRs in response to repetitive stimulation in controlled conditions. Neurotransmitter release was mimicked on outside-out patches from 50-hour-old zebrafish hindbrain Mauthner cells using fast-flow application techniques (Legendre, 1998). Glycine at 0.3-3 $\mathrm{mM}$ was applied in pulses of duration $1 \mathrm{~ms}$ at frequencies ranging from 0.5 to $4 \mathrm{~Hz}$. We show that an increase in the application frequency $(\geq 1 \mathrm{~Hz}$ ) results in a reversible decrease in the amplitudes of those synaptic-mimicked currents. 


\section{METHODS}

The experiments have been carried out in accordance with the Declaration of Helsinki and conform to the European Community guiding principles in the care and use of animals (86/609/CEE, CE off $\mathrm{J} n^{\circ} \mathrm{L} 358,18$ December 1986), the French decree ${ }^{\circ} 97 / 748$ of October 19, 1987 (J. Off. République Française, 20 October 1987, pp. 12245-12248) and the recommendations of CNRS and University Paris VI.

\section{Isolated intact brain preparation}

The isolated hindbrain of the zebrafish was prepared as previously described (Legendre \& Korn, 1994). Briefly, the hindbrains of 50 to 60 -hour-old larvae were dissected out and glued to a coverslip using a plasma-thrombin embedding procedure. Before starting the experiments, brain preparations were stored for $15 \mathrm{~min}$ in an oxygenated $\left(100 \% \mathrm{O}_{2}\right)$ bathing solution containing (in $\mathrm{mM}$ ): $\mathrm{NaCl} 145 ; \mathrm{KCl} 1.5 ; \mathrm{CaCl}_{2} 2 ; \mathrm{MgCl}_{2} 1$; glucose 10 , HEPES 10 (pH 7.3) with the osmolarity adjusted to $300 \mathrm{mOsm}$.

\section{Outside-out patch clamp recordings}

Standard outside-out recordings (Hamill et al., 1981) were achieved under direct visualization (Nikon Optiphot microscope) of the Mauthner cells (M-cell). The isolated brain was continuously perfused at room temperature $\left(20^{\circ} \mathrm{C}\right)$ in the recording chamber $(0.5 \mathrm{ml})$ with an oxygenated bathing solution $\left(2 \mathrm{ml} / \mathrm{min}\right.$ ) containing (in $\mathrm{mM}$ ): $\mathrm{NaCl} 145 ; \mathrm{KCl} 1.5 ; \mathrm{CaCl}_{2} 2$; $\mathrm{MgCl}_{2}$ 1; glucose 10, HEPES 10 (pH 7.3) with the osmolarity adjusted to 300 mOsm. Patchclamp electrodes were pulled from thick-wall borosilicate glass and had typical resistances of 10-15 M $\Omega$. They were fire-polished and filled with a solution containing (in $\mathrm{mM}$ ): $\mathrm{CsCl} 135$; $\mathrm{MgCl}_{2} 2 ; \mathrm{Na}_{3} \mathrm{ATP} 4$ 4; EGTA 10; HEPES 10; $\mathrm{pH}$ 7.2. The osmolarity was adjusted to 
290 mOsm. Outside-out patches were obtained by slowly pulling out the pipette. The resistance of outside-out patches ranged from 5 to $10 \mathrm{G} \Omega$. Currents were recorded using an Axopatch 1D amplifier (Axon instruments). Outside-out currents were filtered at $5 \mathrm{kHz}$ using an eight-pole Bessel filter (Frequency Devices), sampled at $50 \mathrm{kHz}$ (Digidata 1200 interface, Axon Instruments, USA) and stored on an IBM AT compatible computer using PClamp software 6.03 (Axon Instruments, USA)

\section{Drug delivery}

Outside-out single channel currents were evoked using a fast-flow application system as previously described (Legendre, 1998). Drugs were dissolved in the bathing solution used to perfuse the preparation. Control and drug solutions were fed by gravity into the two channels of a glass theta tube ( 2 mm O.D., $200 \mu \mathrm{m}$ tip diameter, Hilgenberg, Germany). One lumen of the tube was connected to a reservoir of control solution. The other lumen was connected using a manifold to 5 different reservoirs to apply different solutions controlled by solenoid valves. Solution exchange was performed by rapidly moving the solution interface across the tip of the patch pipette, using a piezo-electric translator (Physics Instrument, model P245.30). Concentration steps of glycine lasting 1-2000 ms were applied at various frequencies depending on the purpose of the experiment. The $20-80 \%$ exchange time was determined after rupturing the seal by monitoring the change in the liquid junction evoked by the application of a control solution diluted by $10 \%$ to the open tip of the patch pipette (Legendre, 1998). The theoretical limit of the solution speed change was estimated using the method of Maconochie and Knight (1989) (see Legendre (1998) for detailed analysis). With a

patch electrode resistance $>5 \mathrm{M} \Omega$ and a tip diameter $<1 \mu \mathrm{m}$, the estimated $20-80 \%$ exchange time was found to be $\leq 0.08 \mathrm{~ms}$. 


\section{Outside-out patch current analysis}

Outside-out currents were analysis offline using Axograph 4.8 software (Axon Instruments, USA). Traces were sampled at $40 \mathrm{kHz}$ and filtered at $2 \mathrm{kHz}$ using a digital filter (Axograph 4.8 software). The amplitude of outside-out currents was measured manually. The activation and the deactivation time course of consecutive outside-out currents evoked by repetitive application of short concentration pulses of glycine, strongly fluctuate due to the small number of channels in the patch $(<80)$ and the stochastic behavior of the receptor (Legendre, 1998; Ali et al., 2000). We therefore analysed changes in the time course of evoked responses on current traces averaged from $\geq 15$ events. The events were aligned on their rising phase at $20 \%$ of their maximum amplitude. For application frequencies $>1 \mathrm{~Hz}$, a set of consecutive outside-out responses was selected after the stabilisation of the peak response amplitude (15 sec: see figure 1). The equation with two exponential components always resulted in a better fit (Legendre, 1998). The same procedure was applied to all exponential fits (see results). To assess desensitization time constants of the desensitization phase of outside-out currents evoked by 2 s concentration steps of glycine, the desensitization phase was fitted with the sum of exponential curves using a simplex algorithm (Axograph software). The presence of one or two exponential curves was tested by comparing the sum of squared errors (SSE) (Legendre, 1998).

\section{Simulations}

Simulations of outside-out currents were performed using Axograph 4.8 (Axon Instruments) on a G4 Macintosh computer. A previously developed kinetic model of GlyRs expressed by M-cells was used (Legendre, 1998) to generate mIPSCs and outside-out 
currents. This kinetic model (see figure 7A) had two equivalent agonist-binding steps and a doubly liganded closed state that provides access to a reluctant doubly liganded closed state. Each doubly liganded closed state can provide access to independent open states (Legendre, 1998). Desensitized states were added to this model to try to reproduce our experimental data. The rate constants linking the 2 desensitized closed states and these states to the bound closed states $\left(d_{\text {off }} d_{2}, r_{2}, d_{3}\right.$ and $r_{3}$, in figure 7A) were adjusted to obtain theoretical responses with a time course similar to the experimental data. To generate simulated currents, the duration and time-course of the glycine concentration pulse was adjusted according to the experimental application, i.e. with exponential ascending and descending time courses $(0.1 \mathrm{~ms}$ time constant: see Legendre, 1998). The number of available channels together with the glycine concentration was adjusted to allow comparison with experimental data. For each trial, GlyR channels were allowed to behave stochastically.

Spontaneous IPSCs were simulated using Axograph 4.8 (Axon instruments) on a G4 Macintosh (sampling rate $0.05 \mathrm{~ms}$ ). Two GlyR kinetic schemes were compared to determine how GlyR desensitization affects spontaneous IPSCs amplitude variations. The first kinetic model contains two desensitization states as shown in figure 7A and the second kinetic model is identical to the first kinetic model except that it did not contain desensitization states. This second model was previously proposed to described postsynaptic glyR behavior on zebrafish M-cells (Legendre, 1998). The number of available GlyRs was set to 200. The glycine concentration pulse had a fast exponential ascending phase (time constant $0.1 \mathrm{~ms}$ ) and a slower exponential descending time course (time constant $0.3 \mathrm{~ms}$ ) to mimic synaptic release (Clements 1996). For simplifications the intrinsic variation of glycine concentration was limited to $10 \%$. For each trial, GlyR channels were allowed to behave stochastically.

To simulate spontaneous IPSC activity, concentration pulses were generated randomly at a mean frequency of $0.5 \mathrm{~Hz}(100$ events: sampling duration $200 \mathrm{sec}), 1 \mathrm{~Hz}(150$ events: 
sampling duration $150 \mathrm{sec}), 2 \mathrm{~Hz}(100$ events: sampling duration $50 \mathrm{sec}), 3 \mathrm{~Hz}(150$ events: sampling duration $50 \mathrm{sec})$ and $4 \mathrm{~Hz}$ (200 events: sampling duration $50 \mathrm{sec})$. Glycine concentration ( $1 \mathrm{mM}$ and $0.3 \mathrm{mM}$ ) was adjusted to obtain two extreme mean GlyR occupation levels of $\approx 80 \%$ and $\approx 30 \%$.

Averaged data are expressed as mean \pm S.E.M., except when stated otherwise. Statistical significance of the data was assessed by means of Wilcoxon test for paired data and of Mann and Whitney test for unpaired data. 


\section{RESULTS}

Two types of glycine-gated channels could be distinguished in outside-out records from the M-cell, on the basis of their main conductance states and their pharmacological properties (Legendre, 1997). Non-stationary kinetic analysis was performed on the GlyR subtype characterised by a single conductance state of 40-46 pS (Legendre, 1998). Single channel conductance were measured on outside-out patches in the presence of a low glycine concentration and during the deactivation phase of transient responses evoked by short concentration pulses of glycine. GlyRs with a single conductance of 40-46 pS are heteromeric GlyR subtypes containing $\alpha$ and $\beta$ subunits (Bormann et al. 1993) and they represent postsynaptic GlyRs (see for review Legendre 2001).

\section{Activation properties of GlyRs can be modulated by the stimulation frequency}

In outside-out patches from zebrafish M-cells, a $1 \mathrm{~ms}$ application of glycine can evoke currents with a time course similar to that of glycinergic mIPSCs recorded from the same cells (Legendre, 1998). In this experimental paradigm, paired-pulse recordings have shown that fast desensitization makes no significant contribution to the time course of outside-out currents evoked by short concentration steps of 1-3 mM glycine (Legendre, 1998; O'Brien \& Berger, 1999). But this lack of paired pulse inhibition cannot exclude that the receptor progressively enters a slow long lived desensitization state when activated repetitively, as may occur in response to presynaptic firing.

To test for such slow adaptative processes, we analyzed the variation with time of the amplitudes of outside-out currents evoked by short $(1 \mathrm{~ms})$ repetitive application $(1-4 \mathrm{kHz})$ of $3 \mathrm{mM}$ glycine. At these frequencies outside-out responses did not overlap.

$$
<<\text { Figure } 1 \text { should be placed here }>>
$$


As shown in figure 1 , short concentration steps (1 ms) of $3 \mathrm{mM}$ glycine applied at a $0.8 \mathrm{~Hz}$ frequency evoked outside-out currents with amplitude that did not decline with time. However, on increasing the frequency of glycine applications to $4 \mathrm{~Hz}$, the amplitude of outside-out currents declined progressively and reached a steady-state level (figure 1B). This decrease was best fitted with a single exponential function (figure 1C). For all experiments, the control response amplitude was obtained by averaging the amplitude of outside-currents evoked at low frequency $(<1 \mathrm{~Hz})$ immediately before increasing the application frequency. The peak amplitudes of individual responses were then normalized to this control response amplitude.

$$
<<\text { Figure } 2 \text { should be placed here }>>
$$

Both the decrease in response amplitudes and the time constant of the amplitude decrease were dependent on the application frequency. Figure 2 summarizes the data for application frequencies of 1, 2, 3 and $4 \mathrm{~Hz}$. Up to an application frequency of $1 \mathrm{~Hz}$, no change in response amplitude was observed. At $2 \mathrm{~Hz}$, amplitudes decreased with time to reach $72.2 \pm$ $5 \%$ of the control amplitude (measured at $0.5 \mathrm{~Hz}$; see above) with a time constant $\left(\tau_{\text {decay }}\right)$ of $10.5 \pm 3.4 \mathrm{~s}(\mathrm{n}=7)$. Increasing the $3 \mathrm{mM}$ glycine application frequency to $4 \mathrm{~Hz}$ evoked a significantly larger decrease in response amplitude $(39.8 \pm 2.5 \%, \mathrm{n}=17$; Mann and Whitney test, $\mathrm{P}<0.01)$ with a significantly smaller $\tau_{\text {decay }}(4.3 \pm 0.7 \mathrm{~s}, \mathrm{n}=17$; Mann and Whitney test, $\mathrm{P}<0.01)$.

\section{$<<$ Figure 3 should be placed here $>>$}

This frequency-dependent decrease in the response amplitude observed at 2-4 $\mathrm{Hz}$ was reversible upon reduction of the application frequency back to $\leq 1 \mathrm{~Hz}$ (figure $3 \mathrm{~A}$ ). In $50 \%$ of the tested patches, the recovery time course could be fitted with a single exponential curve (figure 3B). In the remaining patches, the recovery time course was linear (data not shown). In patches with exponential amplitude recovery time course, the recovery time constant $\left(\tau_{r}\right)$ 
was independent of the stimulation frequency (figure 3C; Mann and Whitney test, $\mathrm{P}>0.1$ ). For example, it was $3.3 \pm 0.34 \mathrm{~s}$ for an application frequency of $2 \mathrm{~Hz}(\mathrm{n}=6)$ and $3.6 \pm 0.97 \mathrm{~s}$ for an application frequency of $4 \mathrm{~Hz}(\mathrm{n}=6)$. Altogether these results suggest that GlyR kinetics may be progressively modified when the receptors are repetitively activated at frequencies $>1 \mathrm{~Hz}$ by short applications $(1 \mathrm{~ms})$ of a saturating concentration of glycine $(3 \mathrm{mM})$.

To determine if the frequency-dependent decrease in response amplitudes was dependent upon saturation of the glycine binding site, similar experiments were repeated with a glycine concentration of $0.3 \mathrm{mM}$. At this concentration and for such short application durations, glycine is known not to saturate its binding sites. Indeed, $1 \mathrm{~ms}$ concentration steps to $0.3 \mathrm{mM}$ glycine were already demonstrated to activate $\approx 50 \%$ only of the available heteromeric $\alpha 1 / \beta$ GlyRs in outside-out patches (Legendre, 1998; O'Brien \& Berger, 1999). This was expected because $1 \mathrm{~ms}$ pulses are too short to evoke a response with a steady state amplitude when the glycine concentration is lower than $1 \mathrm{mM}$ (Legendre, 1998).

$$
<<\text { Figure } 4 \text { should be placed here }>>
$$

An open probability of GlyR close to 0.5 implies a maximal variance of peak current amplitudes in outside-out records. Accordingly, we observed a high fluctuation between trials of the peak amplitudes of outside-out currents evoked by $1 \mathrm{~ms}$ concentration steps of $0.3 \mathrm{mM}$ glycine (figure 4A). When the application frequency was increased to $4 \mathrm{~Hz}$, the amplitudes of the outside-out currents however still declined with time (figure 4B). The mean current amplitude was $44.6 \pm 4.8 \%(n=5)$ and decreased with a time constant of $5.9 \pm 1.3 \mathrm{~s}(\mathrm{n}=5$; figure 4C). These values were not significantly different from those obtained with a saturating concentration of glycine (Mann and Whitney test, $\mathrm{P}>0.1$ ). 


\section{Desensitization mechanisms and frequency dependent decrease in peak response amplitude}

One mechanism that could account for this reversible decrease in peak amplitude during repetitive application of glycine is the slow entry of receptors into a long-lived desensitization state. Indeed, native heteromeric $\alpha / \beta$ GlyRs are known to slowly desensitize during whole-cell or outside-out recordings (Legendre, 1998; Harty \& Manis, 1998). In our experiments, a $2 \mathrm{~s}$ application step of $3 \mathrm{mM}$ glycine evoked an outside-out current that declined with time to a steady-state current of $21.8 \pm 2 \%(n=8)$ of the peak current amplitude. This decrease in current amplitude with time was best fitted on individual traces with a single exponential curve of time constant close to $0.8 \mathrm{~s}(0.752 \pm 0.053 \mathrm{~s} ; \mathrm{n}=8)$ (figure 5). When traces were averaged, however, a faster component with a time constant of $\approx 30 \mathrm{~ms}$ could be observed (Legendre, 1998), which represented less than $10 \%$ of the desensitized current. This small fast component has been proposed to reflect the time to reach the equilibrium between a willing and a reluctant gating mode leading to two independent open states (Legendre, 1998; Legendre, 1999). It was difficult to detect in individual traces, perhaps due to the small number of activated channel in a patch and to the stochastic behavior of the channel between trials.

$$
<<\text { Figure } 5 \text { should be placed here }>>
$$

To determine if the progressive decrease in the peak amplitude observed during $1 \mathrm{~ms}$ applications of $3 \mathrm{mM}$ glycine at $4 \mathrm{~Hz}$ can impair slow GlyR desensitization kinetics, we first analyzed the amplitude and the time course of currents evoked by $2 \mathrm{~s}$ application of $3 \mathrm{mM}$ glycine ('long' current) before (control responses) and immediately after repetitive applications $(1 \mathrm{~ms}$ at $4 \mathrm{~Hz})$ of $3 \mathrm{mM}$ glycine. As shown in figure $5 \mathrm{~A}$, the peak amplitude of the 'long' current evoked immediately after $4 \mathrm{~Hz}-1 \mathrm{~ms}$ applications of glycine was similar to the preceding currents evoked by $1 \mathrm{~ms}$ concentration steps, i.e. decreased when compared to control currents. When $2 \mathrm{~s}$ pulses were applied at $0.1 \mathrm{~Hz}$, the peak amplitude of the 'long' 
current re-increased to reach a value closely similar to the one of the 'long' current evoked before the $1 \mathrm{~ms}$ applications of $3 \mathrm{mM}$ glycine at $4 \mathrm{~Hz}$ (figure 5B). This decrease in response amplitude was not associated with any significant change (Wilcoxon test, $\mathrm{P}<0.1$ ) in the desensitization time constant or in the relative amplitude of the steady-state current (figure 5C). Immediately after the $4 \mathrm{~Hz}-1 \mathrm{~ms}$ application protocol, the desensitization time constant and the relative steady-state current amplitude were $0.769 \pm 0.08 \mathrm{~s}$ and $20.5 \pm 1.9 \%(\mathrm{n}=8)$, respectively. This result indicates that readily available GlyRs after $4 \mathrm{~Hz}$ repetitive stimulations had closely similar desensitization kinetics than the whole GlyR population.

$$
<<\text { Figure } 6 \text { should be placed here }>>
$$

We next asked how repetitive stimulation influenced recovery from desensitization. As shown in figure $6 \mathrm{~A}$, when $4 \mathrm{~Hz}-1 \mathrm{~ms}$ applications of $3 \mathrm{mM}$ glycine were performed immediately after a 2 s concentration step of glycine, the recovery of the peak amplitude was not complete and only represented $68.5 \pm 2.7 \%(n=8)$ of the peak amplitude of the test response evoked by the preceding $2 \mathrm{~s}$ glycine application. The time constant of the restoration in amplitude was $0.75 \pm 0.04 \mathrm{~s}(\mathrm{n}=8$; figure $6 \mathrm{~B}$ and $\mathrm{C})$. Decreasing the application frequency back to $\leq 1 \mathrm{~Hz}$ resulted in a full recovery of the peak current amplitude (figures $6 \mathrm{~A}$ ). These results indicate that a recovery from desensitization can occur after a $2 \mathrm{sec}$ pulse of glycine during a $4 \mathrm{~Hz}$ train of $1 \mathrm{~ms}$ pulse of glycine, but also that this recovery is partial, suggesting that some receptors have already entered a desensitized state even when activated by a short pulse of glycine.

\section{A minimal Markov model can predict the frequency-dependent decrease of outside-out current amplitudes}

To test whether a long-lived desensitized state can account for stimulation frequencydependent changes in outside-out current amplitude and time course, we have adapted a 
kinetic scheme (figure 7A) previously used to describe zebrafish heteromeric GlyRs behavior (Legendre, 1998; Legendre, 1999; Suwa et al., 2001). This kinetic scheme originally contained two binding closed states and two doubly liganded closed states each being linked together and with separate open states (see figure 7A). This simplified kinetic scheme provided a good description of the behavior of heteromeric GlyR of zebrafish hindbrain. (Legendre, 1998; Legendre, 1999; Suwa et al., 2001). We first modified this kinetic scheme by adding a single desensitized state linked to the fully liganded closed state (2AD in figure 7A), given that the frequency effect did not depend on glycine concentration. The desensitization $(\mathrm{d} 2)$ and the recovery rates $(\mathrm{r} 2)$ were optimized $\left(\mathrm{d} 2=70 \mathrm{~s}^{-1}\right.$ and $\left.\mathrm{r} 2=0.25 \mathrm{~s}^{-1}\right)$ to give a desensitization time constant value and a steady-state to peak current ratio close to the experimental values $(0.58 \mathrm{~s}, 15 \%)$. Outside-out currents generated with this scheme agreed with experimental data in displaying a reduction in current amplitudes at simulated application frequencies of $4 \mathrm{~Hz}(34.4 \%)$. However, it also generated long bursts of openings after deactivation, which were not present experimentally (Data not shown). This is most likely due to the single escape route from $2 \mathrm{AD}$ to $2 \mathrm{AC}$ (figure 7A) and to the fact that GlyRs can reopen several times (from 2AC) before glycine dissociates from its binding site (Legendre 1998). To overcome this problem, the probability for the receptor to escape from the desensitization state via the doubly liganded closed $2 \mathrm{AC}$ should be decreased. We therefore added a mono-liganded desensitized state $(\mathrm{A}+\mathrm{AD})$ both linked to the mono-liganded closed state $(\mathrm{A}+\mathrm{AC})$ and to the doubly liganded desensitized state (2AD) (cyclic scheme; figure 7A). Such a cyclic scheme has been proposed for $\mathrm{GABA}_{\mathrm{A}} \mathrm{R}$ (Jones \& Westbrook, 1995). Optimization of the rate constants, with respect to microscopic reversibility (the product of the rate constants going one way around the cycle being the same as the product of rate constants going the other way around), gave the following values: desensitization $\left(d_{2}\right)$ and recovery $\left(r_{2}\right)$ between $2 \mathrm{AC}$ and $2 \mathrm{AD}$ were $48 \mathrm{~s}^{-1}$ and $0.184 \mathrm{~s}^{-1}$; desensitization $\left(d_{3}\right)$ and 
recovery $\left(r_{3}\right)$ between $\mathrm{A}+\mathrm{AC}$ and $\mathrm{A}+\mathrm{AD}$ were $6.24 \mathrm{~s}^{-1}$ and $0.24 \mathrm{~s}^{-1}$; the association $\left(k_{o n}\right)$ and dissociation $\left(d_{o f f}\right)$ rate constants were $8 \mu \mathrm{M}^{-1} \cdot \mathrm{s}^{-1}$ and $290 \mathrm{~s}^{-1}$ (figure 6A). This kinetic scheme also predicts a progressive inhibition of the successive currents evoked by $4 \mathrm{~Hz}-1 \mathrm{~ms}$ repetitive application of $3 \mathrm{mM}$ glycine down to $31 \%$ with a time constant of $2.84 \mathrm{sec}$ and a recovery time constant of $3.9 \mathrm{sec}$ when the application frequency was decreased back to 0.5 $\mathrm{Hz}$, being in reasonably good agreement with our experimental data. Accordingly, this model made similar predictions to the simpler model for the frequency-dependent decrease in response amplitudes but, as expected, burst openings at the end of deactivation were eliminated.

\section{$<$ Figure 7 should be placed here $>>$}

However this model failed to predict a different recovery time constant $(\approx 0.8 \mathrm{~s})$ as observed during $4 \mathrm{~Hz} 1 \mathrm{~ms}$ glycine concentration steps applied after long glycine pulses (figure 6 ) when compared to the recovery time constant $(\approx 4 \mathrm{~s})$ measured during $0.5 \mathrm{~Hz} 1 \mathrm{~ms}$ glycine concentration steps evoked immediately after $4 \mathrm{~Hz} 1 \mathrm{~ms}$ glycine applications (figure 3). Effectively, changing the recovery rate from $\mathrm{A}+\mathrm{AD}$ and from $\mathrm{A} 2 \mathrm{D}$ in this cyclic scheme with respect to microscopic reversibility did not help to solve this problem and this kinetic scheme always predicts identical recovery time constants for the two protocols. Adding a second desensitization close stated A2D2 linked to the fully liganded desensitization A2D as previously proposed for homomeric $\alpha 1$ GlyRs (Gentet $\&$ Clements, 2002) did not resolve this issue. However this desensitization state A2D2 was necessary to restore the experimentally observed GlyR desensitization time constant values $(\approx 0.02 \mathrm{~s}$ and $\approx 0.5 \mathrm{~s}$; Legendre 1998) and the proportion of desensitized current $(\approx 80 \%)$ during a 2 s glycine concentration pulse when the recovery rate from $\mathrm{A}+\mathrm{AD}$ and from $\mathrm{A} 2 \mathrm{D}$ were adjusted to obtain a fast recovery time constant of $\approx 0.8 \mathrm{~s}$ as observed after the $2 \mathrm{~s}$ glycine concentration pulse (figure 6 ). 
Slow (3-6 s) and faster (0.6-0.8 s) recovery time constants could reflect the presence of an additional independent, rather than sequential, desensitization state. We then tested a model with an additional desensitization state $(\mathrm{A}+\mathrm{AD} 2)$ linked to the mono liganded desensitization state $\mathrm{A}+\mathrm{AD}$ (figure 7A). Effectively, this model could correctly predict a difference in the desensitization time constant value after a 2 s glycine pulse and after repetitive $4 \mathrm{~Hz} 1 \mathrm{~ms}$ glycine applications. In this model the optimization of the rate constants, with respect to microscopic reversibility, gave the following values: desensitization $\left(\mathrm{d}_{2}\right)$ and recovery $\left(\mathrm{r}_{2}\right)$ between $2 \mathrm{AC}$ and $2 \mathrm{AD}$ were $60 \mathrm{~s}^{-1}$ and $0.8 \mathrm{~s}^{-1}$; desensitization $\left(\mathrm{d}_{3}\right)$ and recovery $\left(\mathrm{r}_{3}\right)$ between $\mathrm{A}+\mathrm{AC}$ and $\mathrm{A}+\mathrm{AD}$ were $7.8 \mathrm{~s}^{-1}$ and $1.03 \mathrm{~s}^{-1}$; the association $\left(\mathrm{k}_{\mathrm{on}}\right)$ and dissociation $\left(\mathrm{d}_{\text {off }}\right)$ rate constants were $8 \mu \mathrm{M}^{-1} \cdot \mathrm{s}^{-1}$ and $288 \mathrm{~s}^{-1}$. The desensitization $\left(\mathrm{d}_{4}\right)$ and recovery $\left(\mathrm{r}_{4}\right)$ between 2AD and 2AD2 were $10 \mathrm{~s}^{-1}$ and $10 \mathrm{~s}^{-1}$ and the desensitization $\left(\mathrm{d}_{5}\right)$ and recovery $\left(\mathrm{r}_{5}\right)$ between $\mathrm{A}+\mathrm{AD}$ and $\mathrm{A}+\mathrm{AD} 2$ were $0.9 \mathrm{~s}^{-1}$ and $0.25 \mathrm{~s}^{-1}$. This kinetic scheme (figure 7A) predicts a progressive inhibition of the successive currents evoked by $4 \mathrm{~Hz}-1 \mathrm{~ms}$ repetitive application of $3 \mathrm{mM}$ glycine down to $36.8 \%$ with a time constant of $\approx 3 \mathrm{~s}$ and a recovery time constant of $\approx 4 \sec$ (figure $7 \mathrm{~B}$ ) when the application frequency was decreased to $0,5 \mathrm{~Hz}$. It also predicts a recovery time constant of $\approx 0.7 \mathrm{~s}$, when $4 \mathrm{~Hz} 1 \mathrm{~ms}$ pulses of glycine are applied after a long concentration pulse of agonist (figure 7D), which agrees rather well with our experimental data. Simulated paired-pulse experiments (data not shown) were also in good agreement with previously published data (Legendre, 1998; Singer \& Berger, 1999), i.e. they predict little $(<5 \%)$ paired-pulse inhibition. Simulated currents (figure $7 \mathrm{C})$ also reproduced the experimental data of Figure 5 quite well, hence supporting the hypothesis that the frequency-dependent decrease in outside-current amplitudes is mainly related to slow GlyR desensitization. The three cyclic models (the cyclic model, the cyclic model with the additional fully liganded desensitized state AD2 and the cyclic model with additional fully liganded desensitized state AD2 and mono liganded desensitized state A+AD2) were also 
compared by fitting idealized traces (with experimental mean time constants), using the protocols described in figures 1 and 6A. Models were then compared using the resulting sum of squared error (SSE) values of the fit (Legendre 1998). The fit with the cyclic model with two additional desensitized states (A+AD2 and A2D2) gave a lower SSE value than the two other models indicating that this kinetic model better predicts our experimental data.

$$
<\text { Figure } 8 \text { should be placed here >> }
$$

Since spontaneous IPSCs also occur randomly, we investigated the impact of GlyR desensitization on IPSC amplitude by simulating randomly occurring spontaneous synaptic activity (see methods). Synaptic events were generated at different mean frequency $(0.5,12$, 3 and $4 \mathrm{~Hz}$ ). Since receptor occupancies can vary strongly at different glycinergic synapses in the zebrafish (Rigo et al. 2003), we tested (see methods) the effect of GlyR desensitization on synaptic activity for the two extremes of receptor occupancy, $30 \%$ and $80 \%$, described in the zebrafish hindbrain (Rigo et al. 2003). For comparison, simulated IPSCs were generated using both the kinetic scheme shown in figure 7A and a GlyR kinetic model without desensitization state, as previously published for zebrafish GlyR (Legendre 1998). Figures 8 A and 8B show examples of simulated IPSCs occurring at a mean frequency of $4 \mathrm{~Hz}$ in conditions of high (figure 8A) and low (Figure 8B) receptor occupancy. When traces were simulated with a kinetic scheme including desensitization states, mean IPSC amplitude decreased linearly with IPSC frequency for both occupancy levels (figure 8C1 and 8D1). However as shown in figure 8C2 and 8D2 the percent decrease in IPSC amplitude was larger when GlyR occupancy was near saturation. For example the mean IPSC amplitude decreased by $\approx 30 \%$ at $4 \mathrm{~Hz}$ when the receptor occupancy was close to $80 \%$, while the reduction was $\approx 19 \%$ when IPSCs were simulated with an occupancy of $30 \%$. These simulations thus suggest that slow receptor desensitization regulates glycinergic synapse efficacy even at low frequencies of synaptic activity. 


\section{DISCUSSION}

In this study, we report changes in the functional properties of zebrafish $\alpha 1 / \beta$ GlyRs during repetitive activation. Using a combination of ultra-fast drug application to outside-out patches and non-stationary single channel analysis, we show that the amplitudes of outsideout currents are sensitive to the glycine application frequency. This progressive decline in responses during repetitive application of glycine at a frequencies below superimposition of outside-out currents and its reversibility strongly suggest the existence of desensitized states in which the receptor progressively enters even during brief activations.

\section{Desensitization and frequency dependent decreased in glycine-evoked response amplitude}

The progressive decline in the response amplitude during repetitive glycine application is unlikely to result from the presence of a closed state with fast on- and slow offrates as for $\mathrm{GABA}_{\mathrm{A}} \mathrm{Rs}$ (Jones \& Westbrook, 1995). Such a fast desensitization component implies that short applications of agonist $(1 \mathrm{~ms})$ may suffice to promote a rapid entry of channels into a desensitized closed state as observed for some GABAA receptors (Jones and Westbrook 1995), which will result in a paired pulse inhibition for short (1 ms) agonist applications (Jones \& Westbrook, 1995). This was not the case for heteromeric GlyRs and both zebrafish and mammal native heteromeric GlyRs (Legendre, 1998; Singer \& Berger, 1999).In zebrafish M-cell (Legendre 1998). However the complex desensitization time course of glycine-evoked current also contains a fast (time constant 15-60 ms) component (time constant 15-30 ms) (Legendre 1998). This desensitization component was also observed in the ventral cochlear nucleus of guinea pig (Harty and Manis 1998). In zebrafish M-cell the fast desensitization component represents only $10 \%$ of the inward current as previously described (Legendre 1998). It represented 20\% in ventral cochlear nucleus of guinea pig (Harty and Manis 1998), The fast desensitization component is unlikely to be involved in 
reducing responses amplitude since paired-pulse experiments with $1 \mathrm{~ms}$ glycine applications provided no evidence for paired pulse inhibition of GlyRs (Legendre, 1998; Singer \& Berger, 1999). In zebrafish, this fast component does not represent a desensitization process but rather reflects the time to reach the equilibrium between the two GlyR open channel gating modes from the fully liganded binding state (Legendre, 1998).

Our kinetic model favors the hypothesis that a small fraction of the receptors may already have entered a long-lived closed state after a single short pulse of agonist, the recovery rate from this desensitized state being slow enough with respect to the application frequency to allow the receptors to accumulate in this closed state. Since the amount of desensitized current increases with glycine concentration for native heteromeric GlyRs (Harty \& Manis, 1998; Legendre, 1998), this could suggest that such a desensitized closed state might be linked to a fully liganded closed state, as for some $\mathrm{GABA}_{\mathrm{A}} \mathrm{R}$ subtypes (Jones and Westbrook 1995 Mozrzymas et al., 2003) or for $\alpha 1$ homomeric GlyRs (Grewer, 1999).This is consistent with our simulations showing that a GlyR kinetic scheme with slow desensitization mechanisms adequately predicts our experimental data. In addition to the fast desensitization component, a second slow $(\approx 0.5 \mathrm{~s})$ and a third ultra slow ( $>2 \mathrm{~s}$ time constant) component was revealed in the ventral cochlear nucleus for glycine applications of durations increased to 9 s (Harty and Manis 1998). Such a slow desensitization component has also been described in whole cell records from isolated rat hypothalamic neurons (Akaike and Kaneda 1989). In our experiments we only observed the intermediate desensitization component for glycine applications of duration 2s (figure 6; Legendre 1998). In one patch, when glycine pulses of duration 10 s were applied, the evoked current declined with time with a desensitization time course best fitted with three exponential curves with time constants of $0.023 \mathrm{~s}(14 \%$ of the peak current $), 0.476$ (65\% of the peak current) $\mathrm{s}$ and $2.8 \mathrm{~s}(1.8 \%$ of the peak current $)$ indicating that zebrafish GlyRs may also possess a long lived desensitization closed state. 
This was also predicted by the kinetic scheme shown in figure 7A. Simulated $10 \mathrm{~s}$ glycine applications generate a current with three desensitization components, the slowest component having a time constant of $3.7 \mathrm{sec}$ and represented $1 \%$ of the peak current only. Accordingly, it is likely that mammalian and zebrafish GlyR have closely similar desensitization behavior that could control glycinergic synapse efficacy even during slow synaptic activity. This hypothesis is consistent with the high homology of aminoacid sequences of mammalian and zebrafish GlyR subunits at the M2 and M1-M2 intracellular loop domain (Imboden et al.1, 2001; Imboden et al.2, 2001), this GlyR subunit domains being likely involved in GlyR desensitization processes (Saul et al. 1999).

Recovery from desensitization of GlyRs was first studied in rat isolated hypothalamic neurons. In these cells the recovery from desensitization analyzed on responses evoked by long pulses $(>5 \mathrm{sec})$ of $1 \mathrm{mM}$ glycine had two components with time constants close to $0.6 \mathrm{~s}$ and 2.5 s (Akaike and Kaneda 1989). Similar values were also described in the ventral cochlear nucleus of guinea pig (0.3 s and $3.5 \mathrm{~s}$; Harty and Manis 1998) and in transfected cells expressing homomeric $\alpha$ GlyRs $\beta$ and heteromeric $\alpha 1 / \beta$ GlyRs $(0.5 \mathrm{~s}$ and $2 \mathrm{~s}$; Mohammadi et al. 2003). These recovery time constant values are comparable to values we measured after $2 \mathrm{~s}$ glycine application $(0.75 \mathrm{~s})$ and after repetitive $4 \mathrm{~Hz} 1 \mathrm{~ms}$ applications $(\approx$ $3.5 \mathrm{~s})$. Accordingly, it is possible that the ultra slow desensitization process mainly account for frequency dependent decrease in response amplitude. Effectively, the partial amplitude recovery observed during repetitive $4 \mathrm{~Hz}$ glycine applications evoked after a $2 \mathrm{~s}$ concentration pulse of glycine had values, similar to those obtained during $4 \mathrm{~Hz}$ repetitive stimulation alone. This could suggest that even at this frequency, GlyRs can partly escape from intermediate desensitization states. The kinetic scheme shown in figure 7A favors this hypothesis. In this model the two recovery rates linking the desensitization states $\mathrm{A}+\mathrm{AD}$ and $\mathrm{A} 2 \mathrm{D}$ to the close states $\mathrm{A}+\mathrm{AC}$ and $\mathrm{A} 2 \mathrm{C}$ mainly control the recovery we observed after $2 \mathrm{~s}$ glycine application 
(figure 7A). A slow recovery of amplitude, such as that observed when glycine was applied at $0.5 \mathrm{~Hz}$ frequency after repetitive $4 \mathrm{~Hz}$ applications, requires the presence of the mono liganded desensitization state $\mathrm{A}+\mathrm{AD} 2$ with slow on and off rates (figure 7A). It is therefore likely that slow desensitization mechanism can significantly control GlyR activity even when short pulses of agonist repetitively activated the receptors. In contrast to the proposal of Overstreet et al. (2000) for the physiological function of slow GABAAR desensitization, this inhibitory GlyR control does not require the presence of a low, basal agonist concentration between agonist application pulses.

\section{GlyR kinetic schemes.}

The kinetic scheme we tested was derived from that previously published for zebrafish heteromeric GlyRs which predict M-cell GlyR behavior reasonably well (Legendre, 1998; Legendre, 1999; Suwa et al., 2001). More complex kinetic models have been proposed to predict heteromeric GlyRs behavior in transfected cells (Burzomato et al., 2004) They contain 3 binding sites, 3 open states and three desensitization state or three binding states and intermediate closed states linking the three binding states to the three open states (Burzomato et al., 2004). These model were somewhat difficult to interpret in term of structure-function according to the recently demonstrated stochiometry of $2 \alpha$ and $3 \beta$ subunits for $\alpha 1 / \beta$ heteromeric GlyRs (Grudzinska et al., 2005), with the glycine binding site at the interface between the $\alpha$ and the $\beta$ subunits (Grudzinska et al., 2005). We have tested these two models to determine if they can also predict the frequency dependent decrease of glycine evoked current amplitude. However, none of these models can predict our experimental data. Nor do they describe a double exponential decay time course for mIPSCs as observed in zebrafish (Legendre, 1998; Legendre, 1999; Suwa et al., 2001). Accordingly, we opted for the GlyR kinetic scheme as a basis for the simulation of outside-out currents. This kinetic scheme 
provided acceptable agreement with our experimental data described, hence supporting the hypothesis that the frequency-dependent decrease in outside-current amplitudes is mainly related to slow GlyR desensitization.

\section{Physiological significance}

Our simulations of randomly occurring IPSCs favor the hypothesis that a slow GlyR desensitization modulates synaptic strength. Our simulation experiments predict that IPSC amplitude could be down regulated by GlyR desensitization in a frequency-dependent manner. We have also shown that such regulation can also occur at low receptor occupancy although to a lesser extent that at high occupancy level. This observation implies that for a given activation frequency, GlyR desensitization can tune glycine synapse strength if the receptor occupancy change. This can be achieve by an increase or a decrease of the basal release probability at presynaptic glycinergic terminals via the activation of presynaptic receptors such as those described on rat spinal sacral dorsal commissural nucleus neurons (Jeong et al. 2003), presynaptic $\mathrm{P}_{2} \mathrm{X}$ receptors in neurons of the Trigeminal Nucleus (Wang et al. 2001) or presynaptic ACh receptors in the rat substancia gelatinosa neurons (Kiyosawa et al. 2001). Although this change may be modest, it can be enhanced if one supposes that GlyR desensitization can also be modulated which is effectively the case. GlyR desensitization is enhanced by receptor phosphorylation (Gantet and Clements 2002) and it has been recently shown that endogenous cannabinoids can accelerate GlyR desensitization in the hippocampus by acting directly on the receptors as do allosteric inhibitors (Lozovaya et al. 2005). Effectively, physiological concentrations of both 2-arachidonylglycerol and anandamide, decrease the time constant of glycine-induced current desensitization to $\approx 50 \%$ (Lozovaya et

al. 2005). We have tested the impact of such an increase in GlyR desensitization by simulating IPSC occurred randomly at an intermediate frequency ( $2 \mathrm{~Hz}$ data not shown). To 
obtain a $50 \%$ decrease in the desensitization time constant, the two desensitization rate constants $\mathrm{d} 2$ and $\mathrm{d} 3$ of the model shown in figure $7 \mathrm{~A}$ were increased to $18.5 \mathrm{~s}^{-1}$ and $150 \mathrm{~s}^{-1}$, respectively. In this case the IPSC amplitude was decreased by $38 \%$ rather than $18 \%$ (see figure 8). The effect of an increase in receptor desensitization on IPSC amplitude was also more pronounced on simulating synaptic events with a low receptor occupancy. In this case, mean IPSC amplitude was decreased by $26 \%$ instead of the $11.7 \%$ previously calculated with slower desensitization rate constants. Accordingly, changes in GlyR desensitization properties are likely to affect IPSC amplitude and thus inhibitory synaptic strength in a way similar to that observed during for example short-term depression.

\section{Conclusions}

In summary, our results show that the repetitive activation of GlyRs at a relatively low frequency induces complex changes that primarily involve slow desensitization mechanisms. Our analysis demonstrates a new physiological role of slow desensitization processes for GlyRs. It contrasts with studies suggesting that slow desensitization only controls receptor activation at high epileptic-like activation frequencies (Gentet and Clements 2002) or when low agonist concentrations are maintained sufficiently long in the synaptic cleft (Overstreet et al., 2000). Our results rather indicate that slow GlyR desensitization may control synaptic efficacy even at low levels of activity in presynaptic glycinergic neurons, as a function of firing frequency, postsynaptic receptor occupancy and the release of allosteric GlyR inhibitors. 


\section{REFERENCES}

Akaike N, Kaneda M. Related (1989) Glycine-gated chloride current in acutely isolated rat hypothalamic neurons. J Neurophysiol. 62:1400-1409.

Ali DW, Drapeau P, \& Legendre P (2000). Development of spontaneous glycinergic currents in the Mauthner neuron of the zebrafish embryo. J Neurophysiol 84, 1726-1736.

Auerbach A, Sigurdson W, Chen J, \& Akk G (1996). Voltage dependence of mouse acetylcholine receptor gating: different charge movements in di-, mono- and unliganded receptors. J Physiol 494, 155-170.

Bormann,J., Rundstrom, N., Betz, H. \& Langosch, D (1993). Residues within transmembrane segment $\mathrm{M} 2$ determine chloride conductance of glycine receptor homo- and hetero-oligomers. EMBO J. 12, 3729-3737.

Burzomato V, Beato M, Groot-Kormelink PJ, Colquhoun D, \& Sivilotti LG (2004). Single-channel behavior of heteromeric alphalbeta glycine receptors: an attempt to detect a conformational change before the channel opens. J Neurosci 24, 10924-10940.

Colquhoun D \& Sakmann B (1985). Fast events in single-channel currents activated by acetylcholine and its analogues at the frog muscle end-plate. J Physiol 369, 501-557.

Clements JD (1996) Transmitter timecourse in the synaptic cleft: its role in central synaptic function. Trends Neurosci 19: 163-171.

Donato R \& Nistri A (2001). Differential short-term changes in GABAergic or glycinergic synaptic efficacy on rat hypoglossal motoneurons. J Neurophysiol 86, 565-574.

Gentet LJ \& Clements JD (2002). Binding site stoichiometry and the effects of phosphorylation on human alpha1 homomeric glycine receptors. J Physiol 544, 97-106.

Grewer C (1999). Investigation of the alpha(1)-glycine receptor channel-opening kinetics in the submillisecond time domain. Biophys J 77, 727-738.

Grudzinska J, Schemm R, Haeger S, Nicke A, Schmalzing G, Betz H, \& Laube B (2005). The beta subunit determines the ligand binding properties of synaptic glycine receptors. Neuron 45, 727-739.

Hamill OP, Marty A, Neher E, Sakmann B, \& Sigworth FJ (1981). Improved patchclamp techniques for high-resolution current recording from cells and cell-free membrane patches. Pflugers Arch 391, 85-100. 
Harty TP \& Manis PB (1998). Kinetic analysis of glycine receptor currents in ventral cochlear nucleus. J Neurophysiol 79, 1891-1901.

Imboden M, De Saint Jan D, Leulier F, Korn H, Goblet C, Bregestovski P. (2001) Isolation and characterization of an alpha 2-type zebrafish glycine receptor subunit. Neuroscience. 2001;103:799-810.

Imboden M, Devignot V, Korn H, Goblet C. (2001) Regional distribution of glycine receptor messenger RNA in the central nervous system of zebrafish. Neuroscience. 103: 811830.

Jeong HJ, Jang IS, Moorhouse AJ, Akaike N. Related (2003) Activation of presynaptic glycine receptors facilitates glycine release from presynaptic terminals synapsing onto rat spinal sacral dorsal commissural nucleus neurons. J Physiol. 550:373-383.

Jones MV \& Westbrook GL (1995). Desensitized states prolong GABAA channel responses to brief agonist pulses. Neuron 15, 181-191.

Kirischuk S, Clements JD, \& Grantyn R (2002). Presynaptic and postsynaptic mechanisms underlie paired pulse depression at single GABAergic boutons in rat collicular cultures. J Physiol 543, 99-116.

Kiyosawa A, Katsurabayashi S, Akaike N, Pang ZP, Akaike N. (2001) Nicotine facilitates glycine release in the rat spinal dorsal horn. J Physiol. 536:101-110.

Krupp J, Bordey A \& Feltz P. (1997) Electrophysiological evidence for multiple glycinergic inputs to neonatal rat sympathetic preganglionic neurons in vitro. Eur J Neurosci. $9: 1711-1719$

Legendre P (1997). Pharmacological evidence for two types of postsynaptic glycinergic receptors on the Mauthner cell of 52-h-old zebrafish larvae. J Neurophysiol 77, 2400-2415.

Legendre P (1998). A reluctant gating mode of glycine receptor channels determines the time course of inhibitory miniature synaptic events in zebrafish hindbrain neurons. J Neurosci 18, 2856-2870.

Legendre P (1999). Voltage dependence of the glycine receptor-channel kinetics in the zebrafish hindbrain. J Neurophysiol 82, 2120-2129.

Legendre P (2001). The glycinergic inhibitory synapse. Cell Mol Life Sci 58, 760-793. 
Legendre P \& Korn H (1994). Glycinergic inhibitory synaptic currents and related receptor channels in the zebrafish brain. Eur J Neurosci 6, 1544-1557.

Lozovaya N, Yatsenko N, Beketov A, Tsintsadze T, Burnashev N. Related (2005) Glycine receptors in CNS neurons as a target for nonretrograde action of cannabinoids. $\mathrm{J}$ Neurosci. 25:7499-7506.

Maconochie DJ \& Knight DE (1989). A method for making solution changes in the sub-millisecond range at the tip of a patch pipette. Pflugers Arch 414, 589-596.

Mangin JM, Baloul M, Prado DC, Rogister B, Rigo JM, \& Legendre P (2003). Kinetic properties of the alpha2 homo-oligomeric glycine receptor impairs a proper synaptic functioning. J Physiol 553, 369-386.

Meyer G, Kirsch J, Betz H, \& Langosch D (1995). Identification of a gephyrin binding motif on the glycine receptor beta subunit. Neuron 15, 563-572.

Mohammadi B, Krampfl K, Cetinkaya C, Moschref H, Grosskreutz J, Dengler R, Bufler J. (2003) Kinetic analysis of recombinant mammalian alpha(1) and alpha(1)beta glycine receptor channels. Eur Biophys J. 32 :529-536.

Mozrzymas JW, Barberis A, Mercik K, \& Zarnowska ED (2003). Binding Sites, Singly Bound States, and Conformation Coupling Shape GABA-Evoked Currents. J Neurophysiol 89, 871-883.

O'Brien JA \& Berger AJ (1999). Cotransmission of GABA and glycine to brain stem motoneurons. J Neurophysiol 82, 1638-1641.

Overstreet LS, Jones MV, \& Westbrook GL (2000). Slow desensitization regulates the availability of synaptic GABA(A) receptors. J Neurosci 20, 7914-7921.

Pagnotta SE, Lape R, Quitadamo C, Nistri A. (2005) Pre- and postsynaptic modulation of glycinergic and gabaergic transmission by muscarinic receptors on rat hypoglossal motoneurons in vitro. Neuroscience. $130: 783-795$.

Rigo JM, Badiu CI, \& Legendre P (2003). Heterogeneity of postsynaptic receptor occupancy fluctuations among glycinergic inhibitory synapses in the zebrafish hindbrain. $\mathrm{J}$ Physiol 553, 819-832.

Saul B, Kuner T, Sobetzko D, Brune W, Hanefeld F, Meinck HM, Becker CM. (1999) Novel GLRA1 missense mutation (P250T) in dominant hyperekplexia defines an intracellular determinant of glycine receptor channel gating. J Neurosci. $19: 869-877$. 
Sigworth FJ \& Sine SM (1987). Data transformations for improved display and fitting of single-channel dwell time histograms. Biophys J 52, 1047-1054.

Sine SM, Claudio T, \& Sigworth FJ (1990). Activation of Torpedo acetylcholine receptors expressed in mouse fibroblasts. Single channel current kinetics reveal distinct agonist binding affinities. J Gen Physiol 96, 395-437.

Singer JH \& Berger AJ (1999). Contribution of single-channel properties to the time course and amplitude variance of quantal glycine currents recorded in rat motoneurons. $\mathrm{J}$ Neurophysiol 81, 1608-1616.

Suwa H, Saint-Amant L, Triller A, Drapeau P, \& Legendre P (2001). High-affinity zinc potentiation of inhibitory postsynaptic glycinergic currents in the zebrafish hindbrain. $\mathrm{J}$ Neurophysiol 85, 912-925.

Wang ZM, Katsurabayashi S, Rhee JS, Brodwick M, Akaike N. (2001) Substance P abolishes the facilitatory effect of ATP on spontaneous glycine release in neurons of the trigeminal nucleus pars caudalis. J Neurosci. 21:2983-2991. 


\section{FIGURE LEGENDS}

Figure 1. The amplitude of glycine-evoked currents recorded in outside-out patches decreases during repetitive fast flow application.

(A) Outside-out currents evoked by repetitive applications (1 ms) of $3 \mathrm{mM}$ glycine at a frequency of $0.5 \mathrm{~Hz}$. (B) Outside-out current evoked by repetitive application (1 ms) of $3 \mathrm{mM}$ glycine at a frequency of $4 \mathrm{~Hz}$. Note that the peak amplitudes of the responses decrease when glycine is applied at a frequency of $4 \mathrm{~Hz}$. (C) Plot of the relative amplitudes of the glycineevoked currents versus time obtained for 0.8 and $4 \mathrm{~Hz}$ application frequencies. Note that the relative amplitudes of the outside-out currents do not change with time when the application frequency is $0.8 \mathrm{~Hz}$ (open circles). Increasing the application frequency to $4 \mathrm{~Hz}$ evokes a decrease in the response amplitudes with time. This decrease in response amplitudes can be fitted by a single exponential function with a time constant of $1.8 \mathrm{~s}$. In this example, the current amplitude is decreased by $30 \%$.

Figure 2. The decrease in current amplitudes with time and the corresponding time constant values depend on the application frequency.

(A) Application frequencies higher than $1 \mathrm{~Hz}$ induce a significant decrease in response amplitudes (1 ms step application of $3 \mathrm{mM}$ glycine). This inhibition increases together with the application frequency. (B) The current inhibition time constant decreases significantly when the application frequency increases.

\section{Figure 3. Recovery from frequency-dependent inhibition.}

(A) Recovery from frequency-dependent inhibition of glycine-evoked responses at $4 \mathrm{~Hz}$ is observed when the frequency of repetitive applications $(1 \mathrm{~ms})$ of $3 \mathrm{mM}$ glycine is set 
back to $0.5 \mathrm{~Hz}$. (B) Recovery time course of the current amplitudes measured from traces shown in A. In $50 \%$ of the patches, the recovery time course could be described by a single exponential curve. In other patches, the recovery time course was linear (not shown). (C) In patches with an exponential amplitude recovery time course, the recovery time constant is independent on the stimulation frequency.

Figure 4. A frequency-dependent current amplitude decrease is also observed for a nonsaturating concentration of glycine.

(A) Example of outside-out currents evoked by repetitive applications of short (1 ms) glycine concentration jumps to $0.3 \mathrm{mM}$. (B) When applied at $4 \mathrm{~Hz}$ (dark circles), $0.3 \mathrm{mM}$ glycine concentration jumps evoke responses that decrease in amplitude with time, which was not observed at $0.5 \mathrm{~Hz}$ (white circles) . (C) The inhibition time constant measured on 5 patches is close to $6 \mathrm{~s}$. The averaged decrease in response amplitude is close to $43 \%$. This is not significantly different from the value obtained for a saturating concentration of glycine (Mann and Whitney test, $\mathrm{P}>0.1$ ).

Figure 5. GlyR slow desensitization kinetics is not modified after $4 \mathrm{~Hz}$ repetitive $1 \mathrm{~ms}$ applications of $3 \mathrm{mM}$ glycine.

(A) Example of outside-out currents evoked by long ( $2 \mathrm{~s}$; stars) concentration jumps to $3 \mathrm{mM}$ glycine before and after $4 \mathrm{~Hz}$ repetitive $1 \mathrm{~ms}$ applications of $3 \mathrm{mM}$ glycine. Note that the amplitude of the current evoked by a $2 \mathrm{~s}$ application of glycine is reversibly decreased when evoked immediately after the end of the $4 \mathrm{~Hz}$ repetitive short applications. (B) Superimposed currents evoked before and after $4 \mathrm{~Hz}$ repetitive short applications. The numbers refer to the responses shown in A. (C) Currents shown in B after normalization with respect to their peak amplitude. Note that the desensitization time courses are not different. 
Figure 6. Recovery from slow desensitization is not complete after $4 \mathrm{~Hz}$ repetitive $1 \mathrm{~ms}$ applications of $3 \mathrm{mM}$ glycine.

(A) Example of outside-out currents evoked by long concentration jumps (2 s) to $3 \mathrm{mM}$ glycine followed by $4 \mathrm{~Hz}$ repetitive $1 \mathrm{~ms}$ applications of $3 \mathrm{mM}$ glycine. Note that current amplitudes evoked by the repetitive application of glycine increase progressively with time but that they do not reach the maximum amplitude value of the peak current evoked by a $2 \mathrm{~s}$ application of glycine. The right trace in A shows a current evoked $10 \mathrm{~s}$ after the end of the $4 \mathrm{~Hz}$ repetitive applications of glycine. Note that the peak amplitude of this current is closely similar to the peak amplitude of the response evoked by the $2 \mathrm{~s}$ glycine application. (B) 10 superimposed traces of the currents evoked after the end of the $2 \mathrm{~s}$ glycine concentration step (stars shown in A). (C) Plot of the peak amplitudes versus time of the currents evoked by $4 \mathrm{~Hz}$ repetitive $1 \mathrm{~ms}$ applications of $3 \mathrm{mM}$ glycine. The increase in current amplitudes with time is fitted by a single exponential curve. Plateau and peak value points refer to the corresponding points in A.

\section{Figure 7. Proposed Markov model for zebrafish GlyRs.}

(A) This model is derived from the Markov model previously proposed for zebrafish heteromeric $\alpha 1 / \beta$ GlyRs (Legendre, 1998). It includes two sequential binding steps (A+AC and $2 \mathrm{AC})$, a reluctant closed state (2AC*) linked to the doubly liganded closed state (2AC), an open state $(2 \mathrm{AO})$ linked to the doubly liganded closed state, another open state $\left(2 \mathrm{AO}^{*}\right)$ linked to the reluctant closed state and a desensitized state (2AD) linked to the doubly liganded closed state. This model also contains a cycle in which an additional desensitized state $(\mathrm{A}+\mathrm{AD})$ linked to the mono-liganded closed state $(\mathrm{A}+\mathrm{AC})$ and to the desensitized state 2AD was added. With this model, a good prediction of the experimental data was obtained 
with the rate constants set to the following values: $\mathrm{k}_{\text {on }}=8 \mu \mathrm{M}^{-1} \mathrm{~s}^{-1}, \mathrm{k}_{\text {off }} 1450 \mathrm{~s}^{-1}, \mathrm{~d}_{\text {off }}=287.5 \mathrm{~s}^{-}$

${ }^{1}, \mathrm{~d}_{1}=800 \mathrm{~s}^{-1}, \mathrm{r}_{1}=100 \mathrm{~s}^{-1}, \mathrm{~d}_{2}=60 \mathrm{~s}^{-1}, \mathrm{r}_{2}=0.8 \mathrm{~s}^{-1}, \mathrm{~d}_{3}=7.8 \mathrm{~s}^{-1}, \mathrm{r}_{3}=1.03 \mathrm{~s}^{-1}, \mathrm{~d}_{4}=10 \mathrm{~s}^{-1}, \mathrm{r}_{4}=10$

$\mathrm{s}^{-1}, \mathrm{~d}_{5}=0.9 \mathrm{~s}^{-1}, \mathrm{r}_{5}=0.25 \mathrm{~s}^{-1}, \beta 1=8940 \mathrm{~s}^{-1}, \alpha 1=700 \mathrm{~s}^{-1}, \beta 2=3600 \mathrm{~s}^{-1}, \alpha 2=1600 \mathrm{~s}^{-1}$.

Simulated outside-out currents generated using $1 \mathrm{~ms}$ pulses of $3 \mathrm{mM}$ glycine applied at a frequency of 0.5 and $4 \mathrm{~Hz}$. Note that the amplitudes of the currents remain stable at $0.5 \mathrm{~Hz}$ while they decrease when the application frequency is increased to $4 \mathrm{~Hz}$. The percent decrease in current amplitudes (35\%) and its decrease time constant value (3.4 s) are closely similar to those obtained experimentally. (C1) Example of simulated outside-out currents evoked by long $(2 \mathrm{~s})$ concentration jumps to $3 \mathrm{mM}$ glycine before and after $4 \mathrm{~Hz}$ repetitive $1 \mathrm{~ms}$ applications of $3 \mathrm{mM}$ glycine. Note that the amplitude of the simulated current evoked by a $2 \mathrm{~s}$ application of glycine is reversibly decreased when evoked immediately after the end of the $4 \mathrm{~Hz}$ repetitive short applications. (C2) Normalized simulated currents shown in $\mathrm{C} 1$ evoked by a $2 \mathrm{~s}$ glycine application evoked before and after $4 \mathrm{~Hz}$ repetitive application of glycine. Note that the model predicts that the desensitization time courses do not differ although current amplitudes were decreased as shown in C1. (D) Example of simulated outside-out currents evoked by long concentration jumps to $3 \mathrm{mM}$ glycine followed by $4 \mathrm{~Hz}$ repetitive $1 \mathrm{~ms}$ applications of $3 \mathrm{mM}$ glycine. Note that current amplitudes evoked by the repetitive application of glycine increase progressively with time but that they do not reach the maximum amplitude value of the peak current evoked by $2 \mathrm{~s}$ application of glycine, again confirming what was experimentally observed.

Figure 8. Frequency-dependent variations in IPSC amplitude during simulated random activity of inhibitory synapses.

A) Example of simulated postsynaptic events evoked by $1 \mathrm{mM}$ glycine ( $80 \%$ receptor occupancy). Left trace: example of simulated events in the absence of GlyR desensitization. 
The kinetic scheme used to generate this traces had identical rate constants than the kinetic scheme shown in figure 7A except that it did not have any desensitization state. Right trace is an example of randomly generated IPSC using the kinetic scheme shown in figure 7A. Note that the amplitude of the synaptic events was decrease when compared to the trace shown in left. B) Example of simulated randomly IPSC activity with low receptor occupancy (30\%) using a kinetic scheme without (left trace) and with desensitization state (right trace). C1) plot of the mean amplitude of simulated IPSCs with high receptor occupancy as a function of their mean occurring frequency. Note that the amplitude of IPSCs decreases linearly with the frequency when the synaptic event were generated using a kinetic scheme including desensitization state. C2) Graph showing the percent decrease in the IPSC mean amplitude as a function of the IPSC frequency. The percent decrease of IPSC amplitude at a given IPSC frequency was calculated according to the corresponding mean amplitude of IPSCs generated using a kinetic scheme without desensitization state. D1) Plot of the mean amplitude of simulated IPSCs with low receptor occupancy as a function of their mean occurring frequency. D2) Graph showing the percent decrease in the IPSC mean amplitude as a function of the IPSC frequency for synaptic events with low receptor occupancy. The percent decrease of IPSC amplitude was calculated as in C2. (C2 and D2). Note that the occupancy level of the receptor slightly influences the frequency-dependent decrease in the IPSC mean amplitude. 
Figure1

Click here to download high resolution image

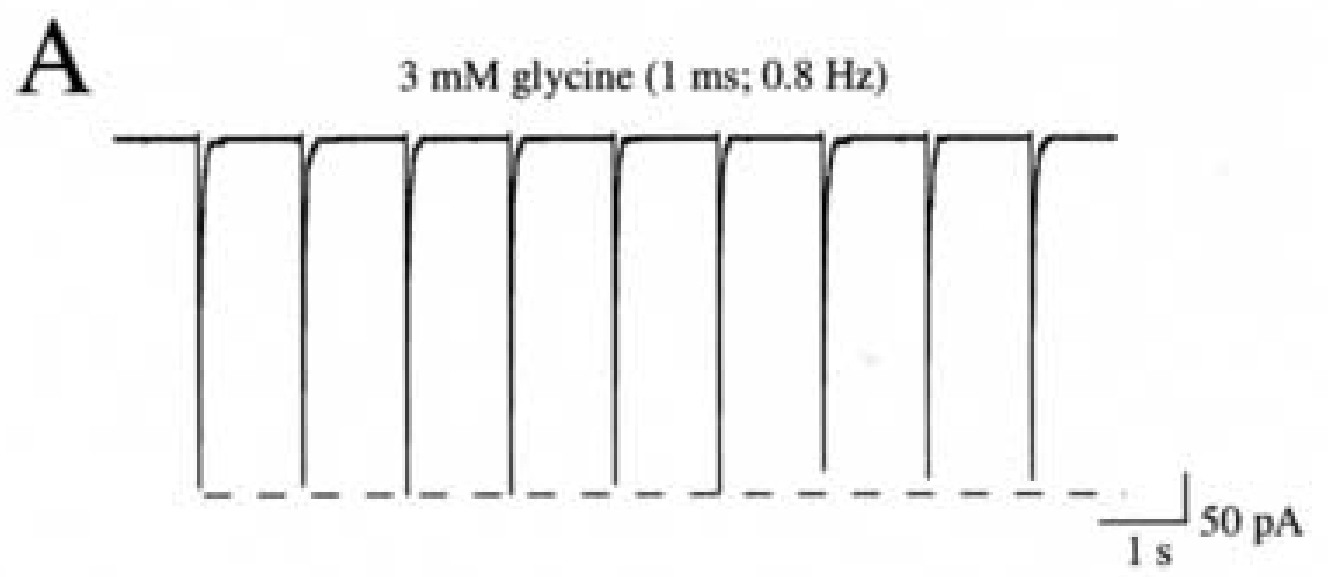

B $3 \mathrm{mM}$ glycine (1 ms; $4 \mathrm{~Hz}$ )
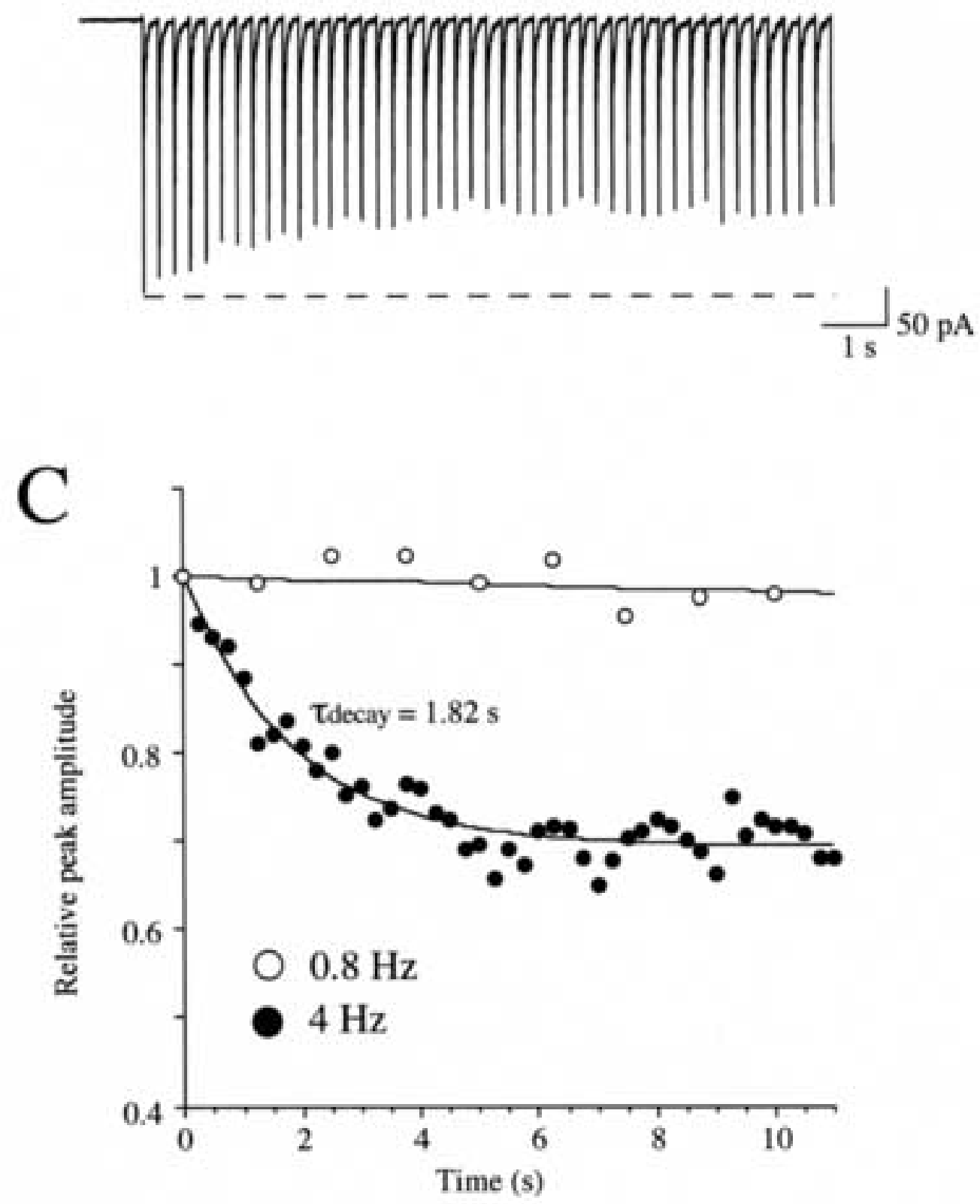


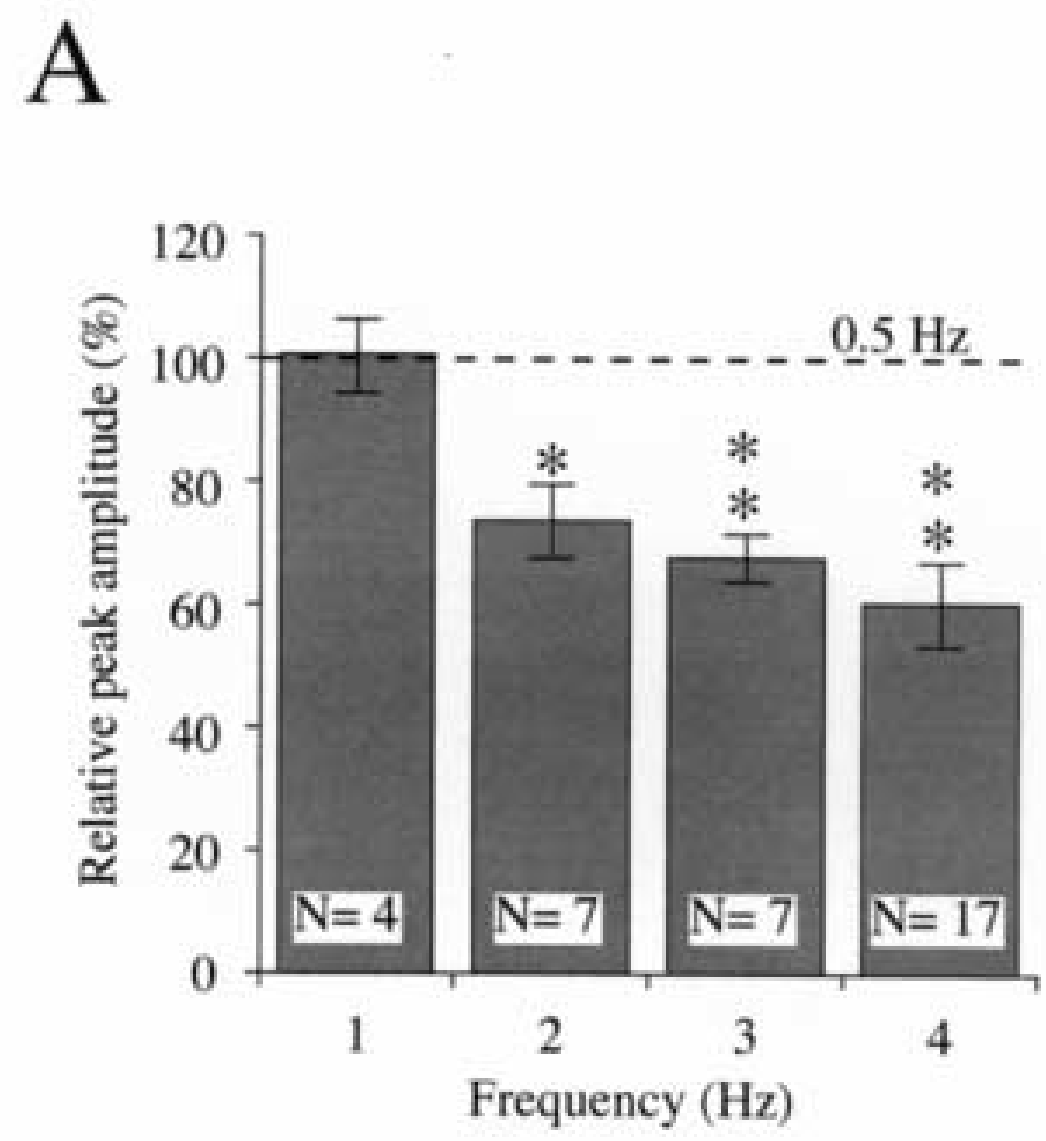

B

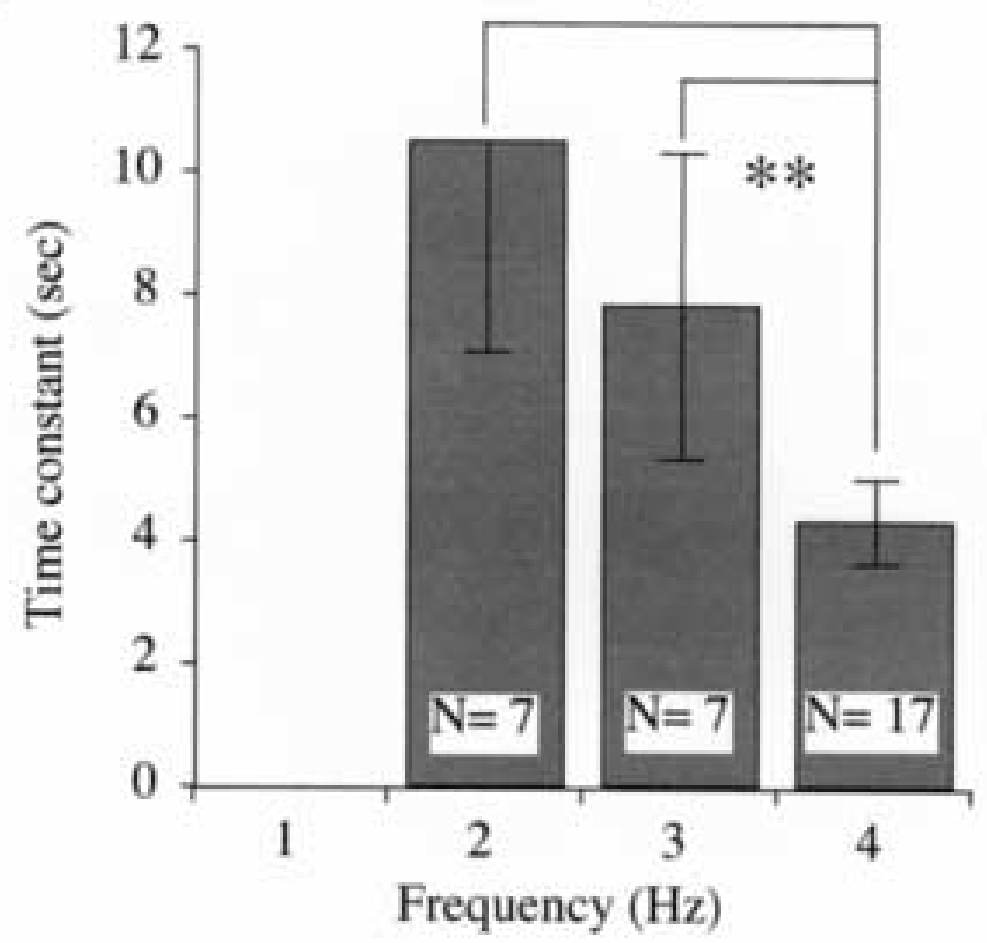


A

$3 \mathrm{mM}$ glycine (I ms; $4 \mathrm{~Hz}$ )

$3 \mathrm{mM}$ glycine (Ims; 0.5Hz)

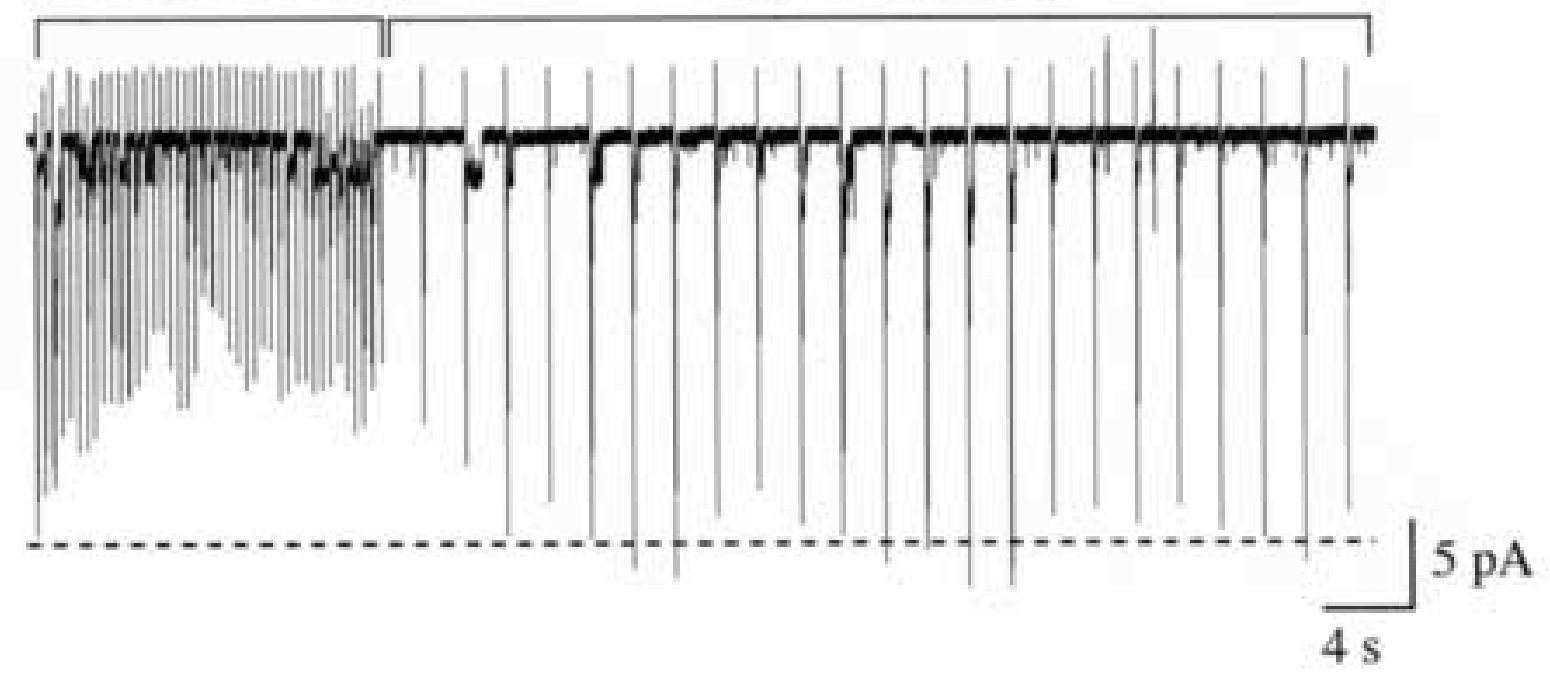

B
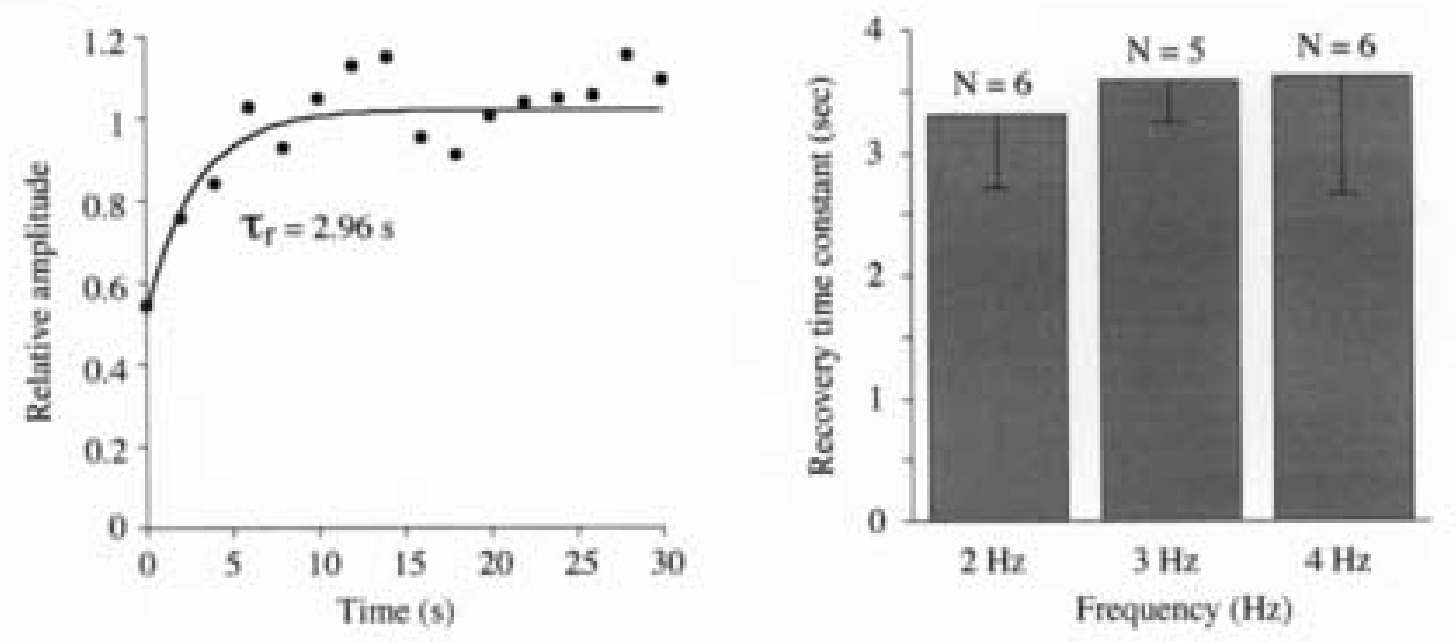

C
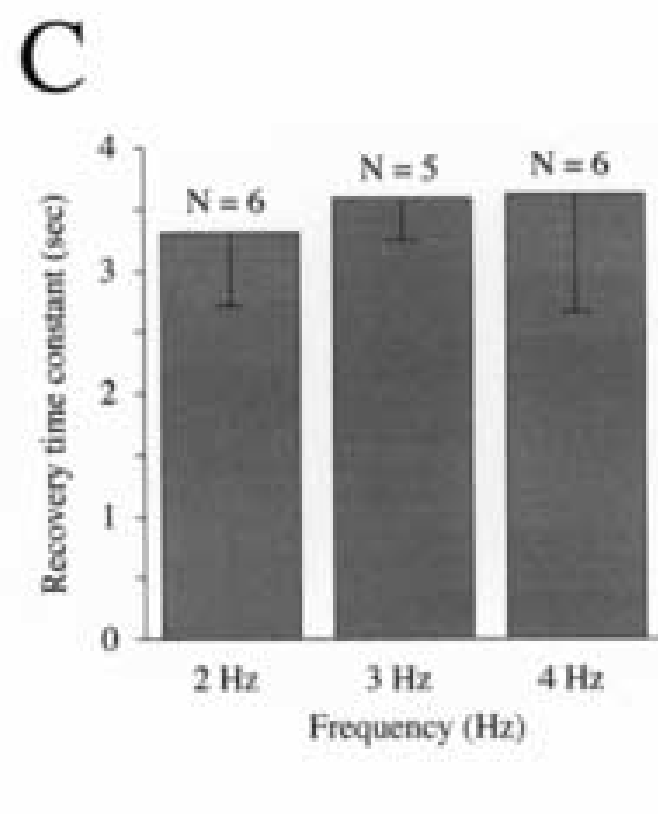


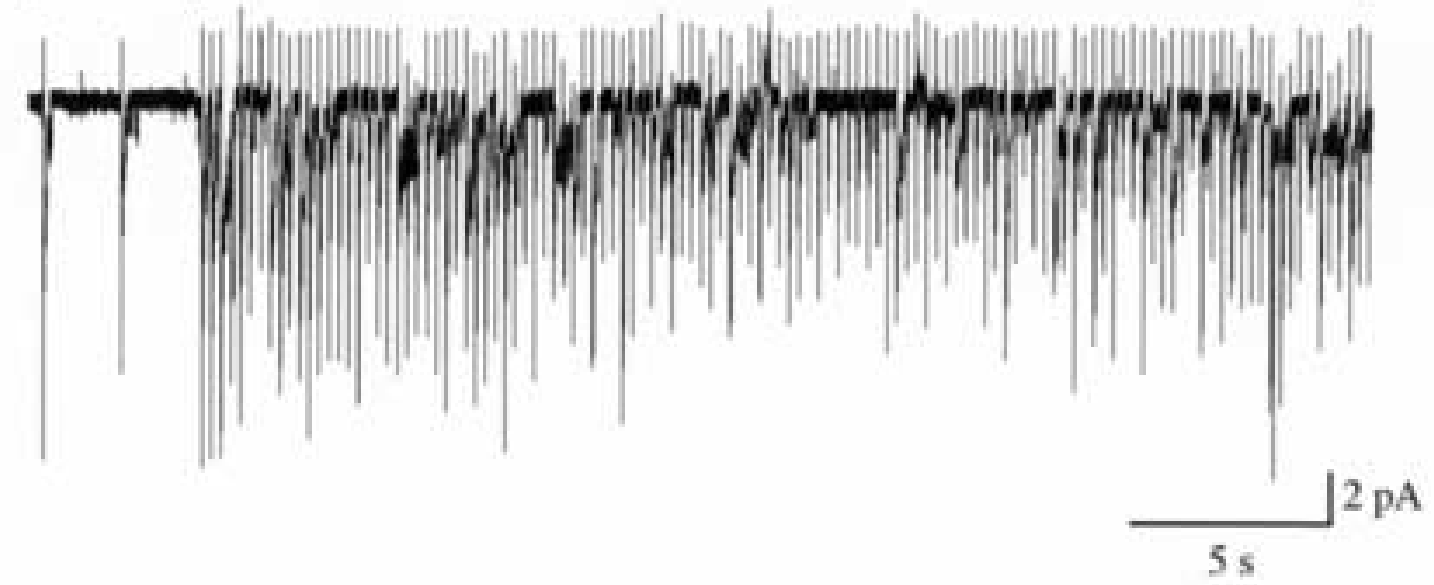

B $\stackrel{0.05 \mathrm{~Hz}}{4}$

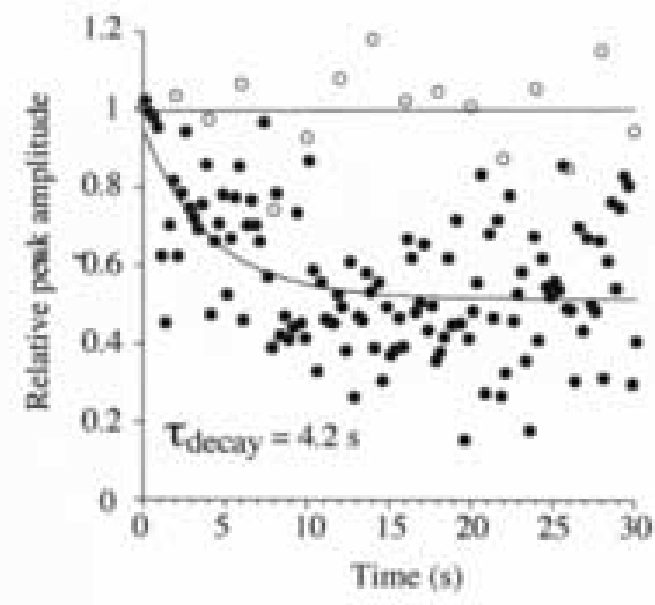

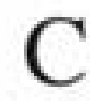
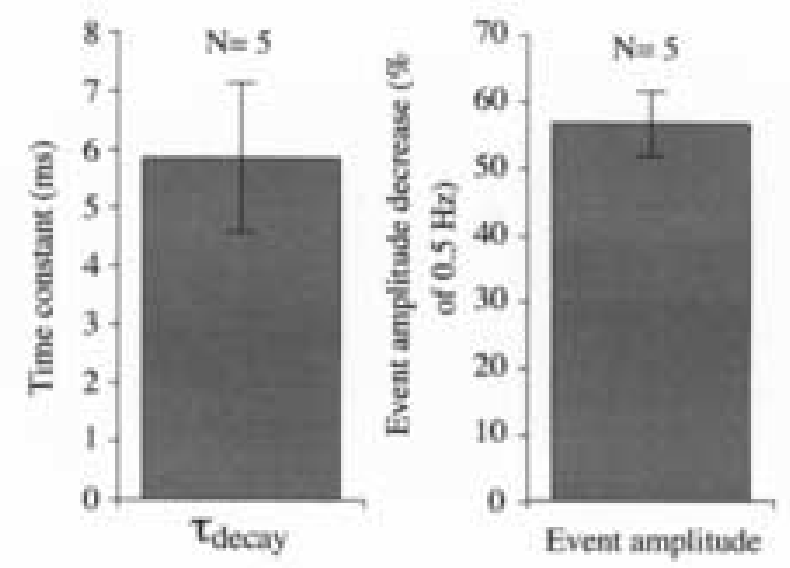
Figure5

Click here to download high resolution image

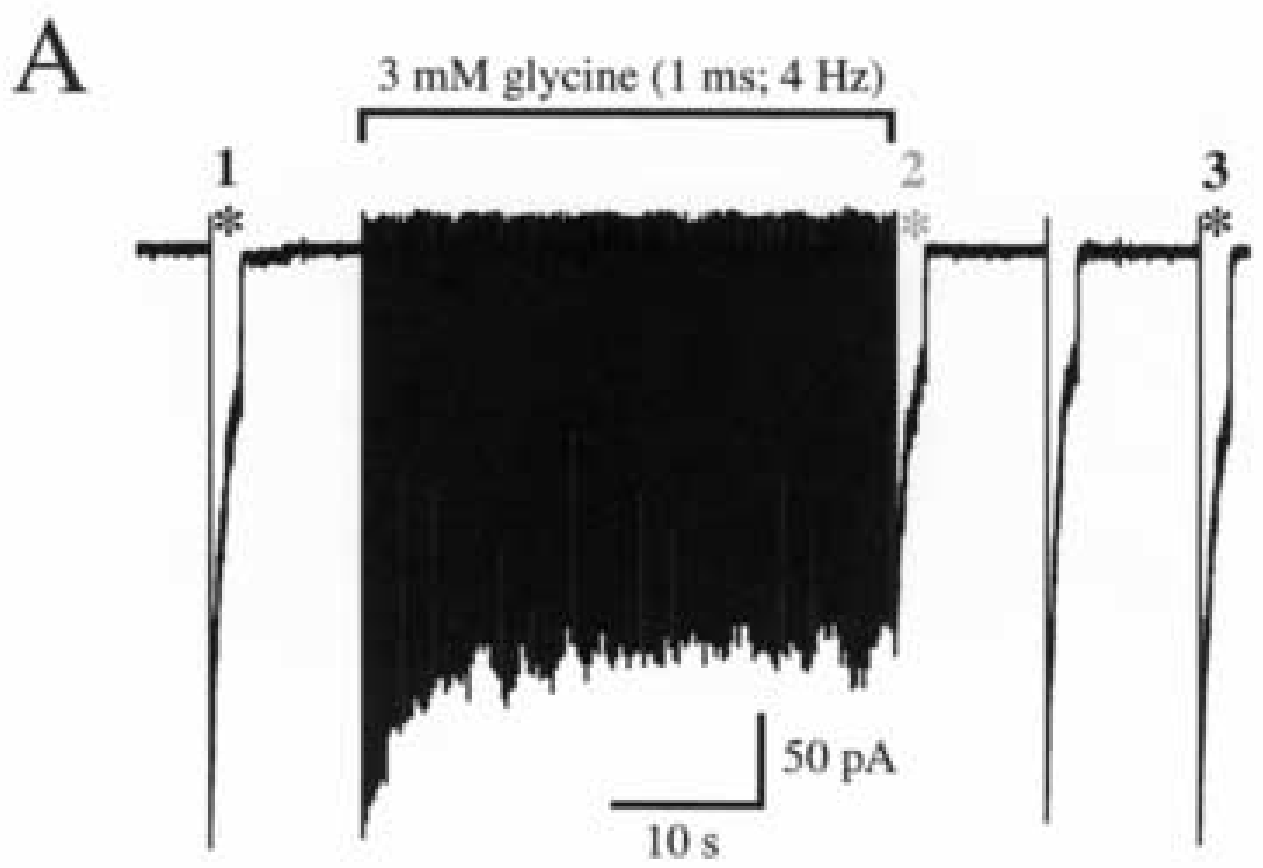

B

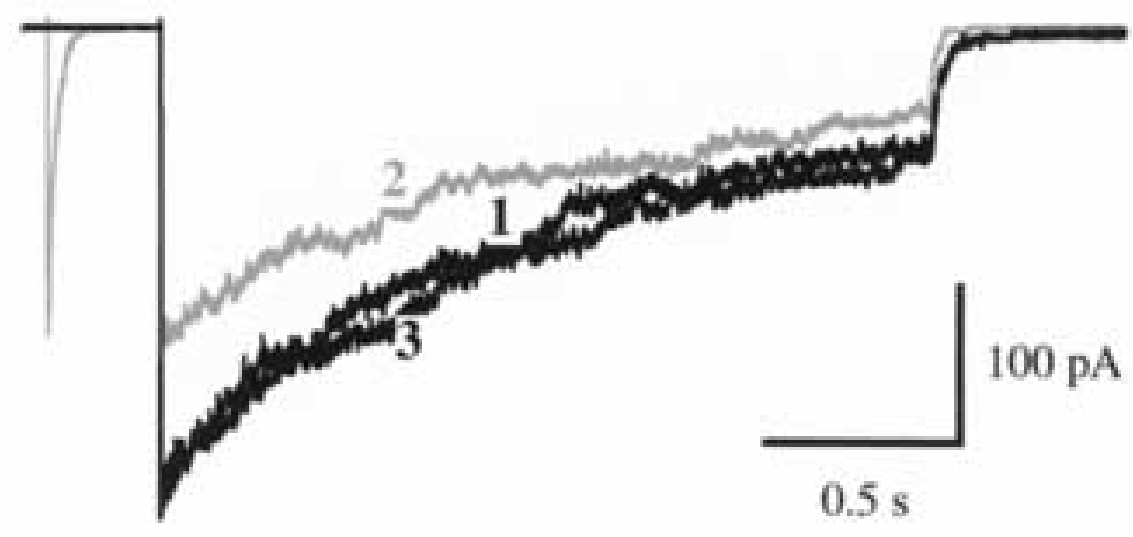

C

Normalized traces

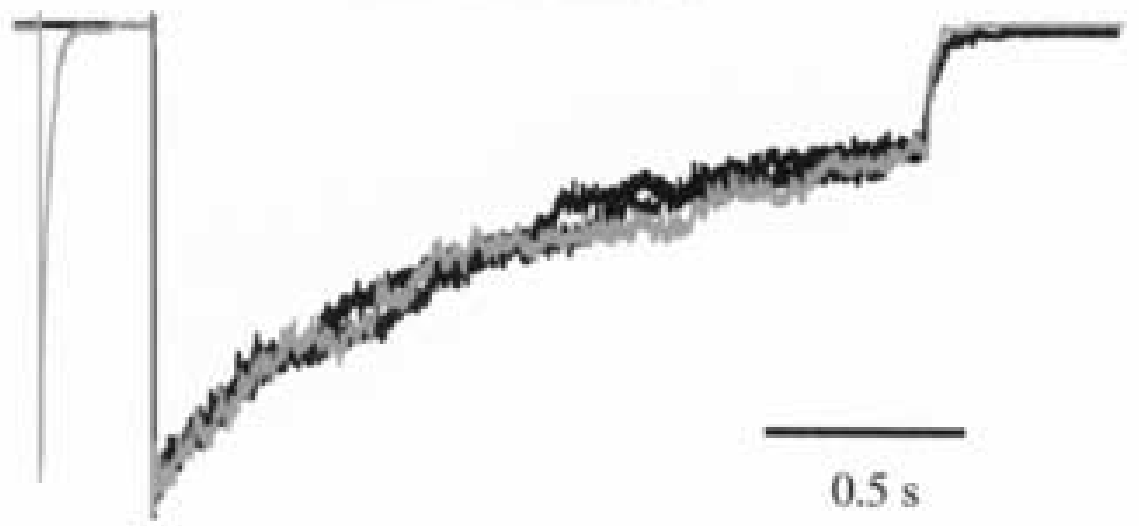


Figure6

Click here to download high resolution image

A

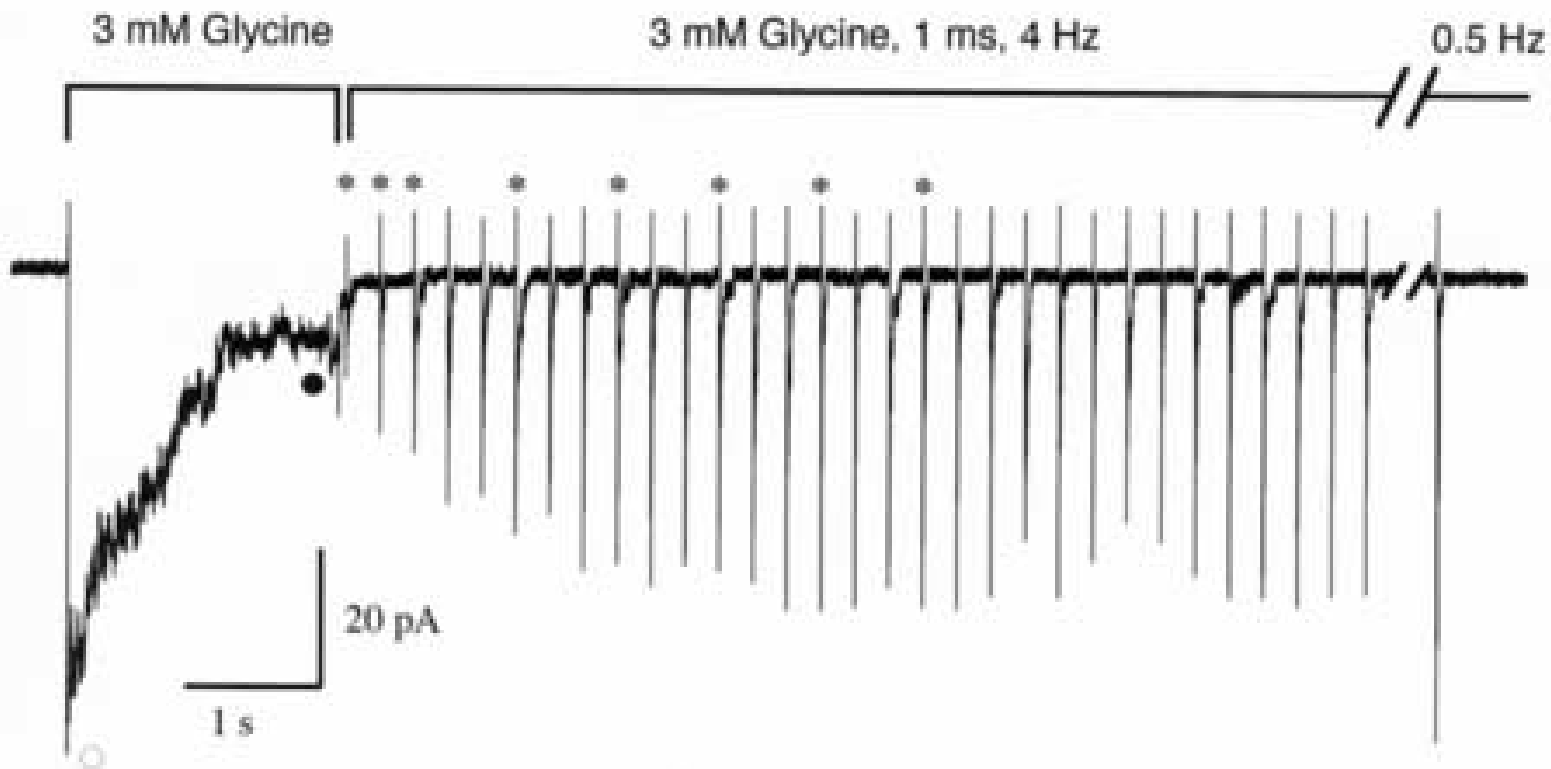

B
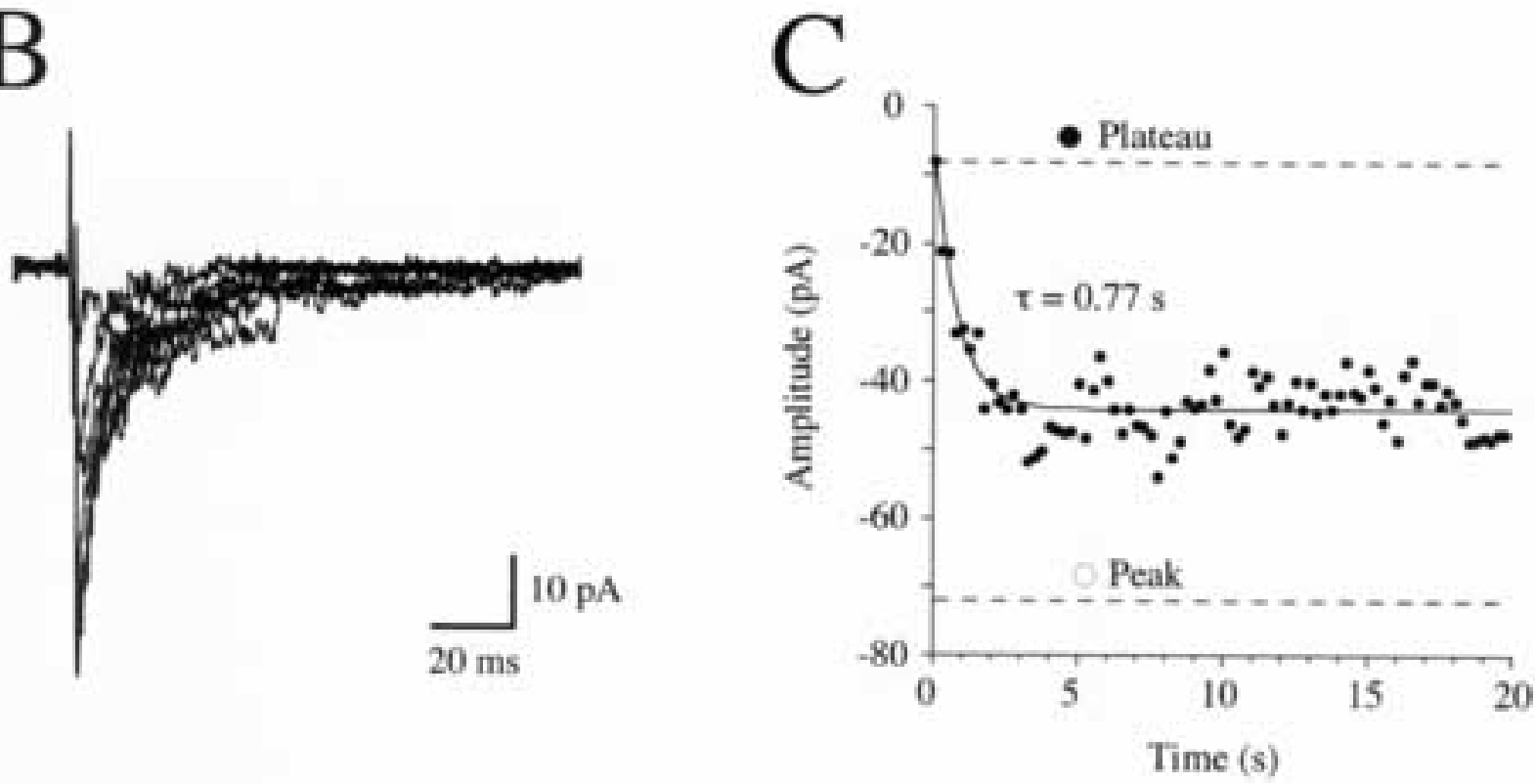
A

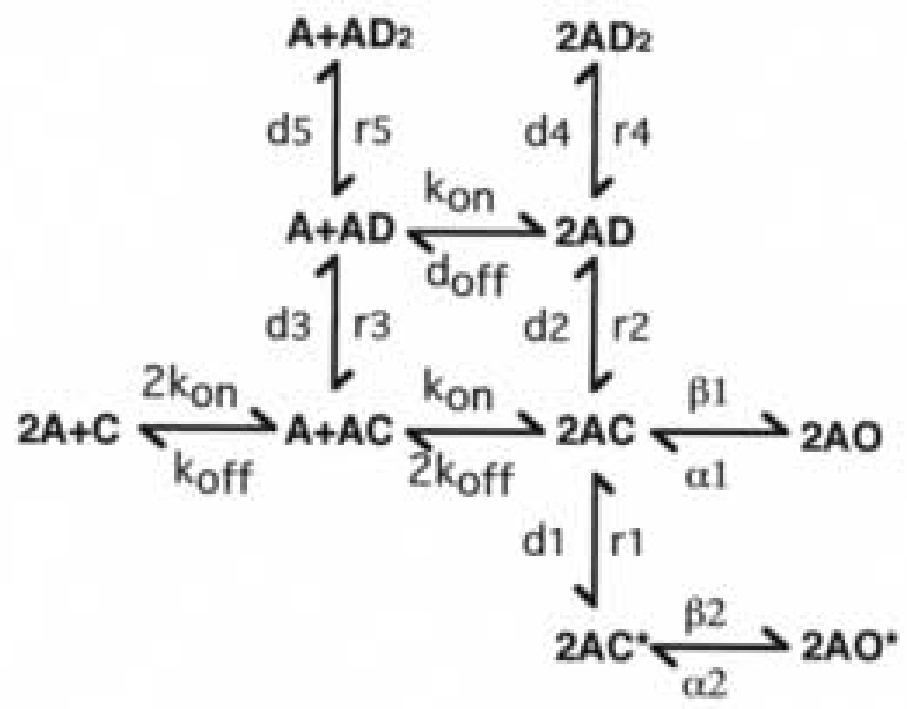

B $3 \mathrm{mM}$ glycine (1 ms)

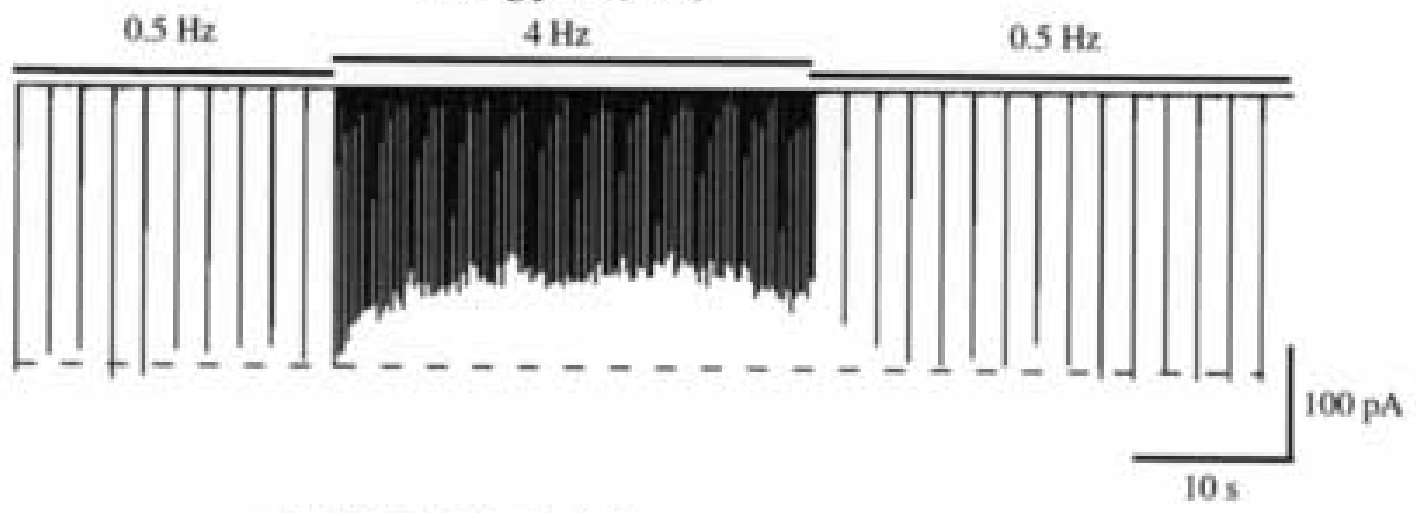

$\mathrm{C}_{1}$

$3 \mathrm{mM}$ glycine (1 ms) $4 \mathrm{~Hz}$

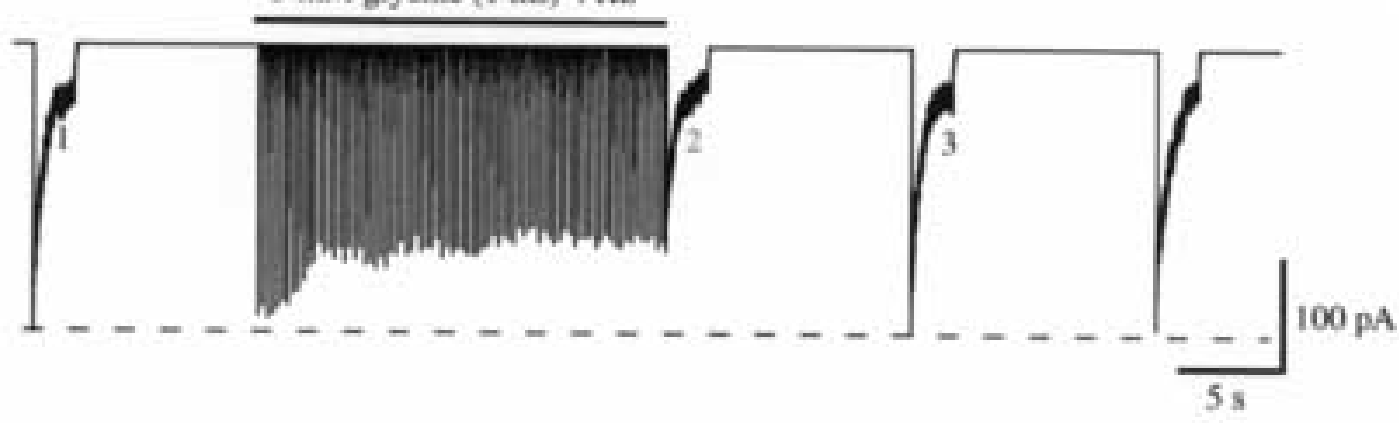

$\mathrm{C}_{2}$

D

$3 \mathrm{mM}$ glycine (1 ms) $4 \mathrm{~Hz}$
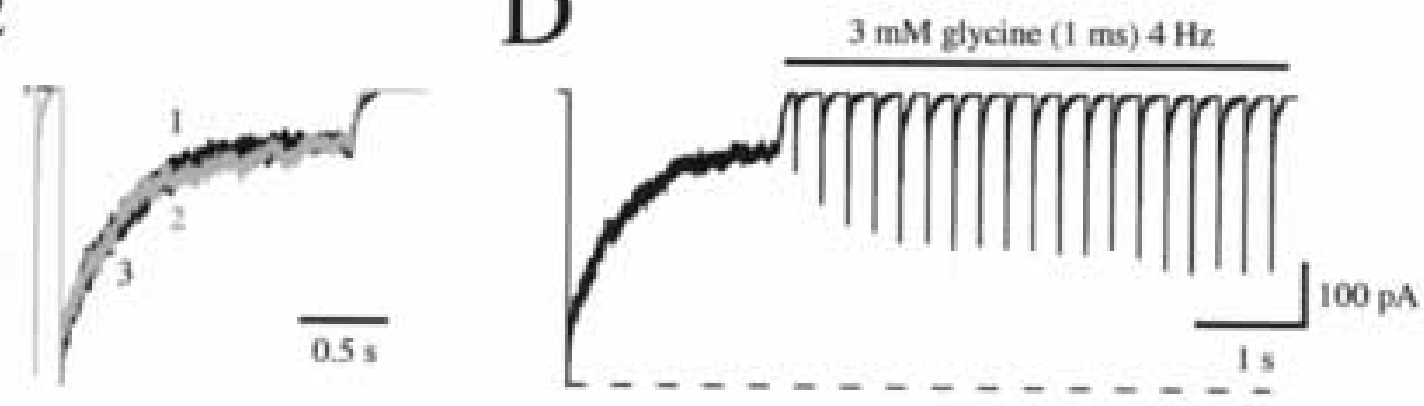
A

$4 \mathrm{~Hz} / \mathrm{mM}$ glycine (no desensitization) $\quad 4 \mathrm{~Hz} / \mathrm{mM}$ glycine (with desensitization)
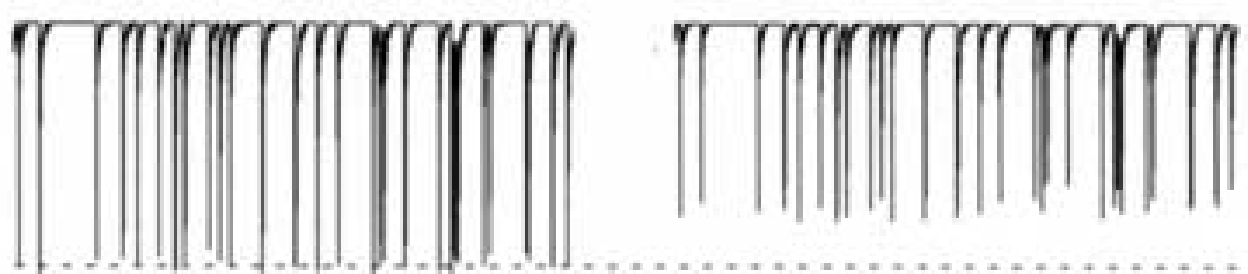

B

$\prod_{i s} 100 \mathrm{pA}$

$4 \mathrm{~Hz} 0.3 \mathrm{mM}$ glycine (no desensitization)

$4 \mathrm{~Hz} .0 .3 \mathrm{mM}$ glycine (with desensitization)
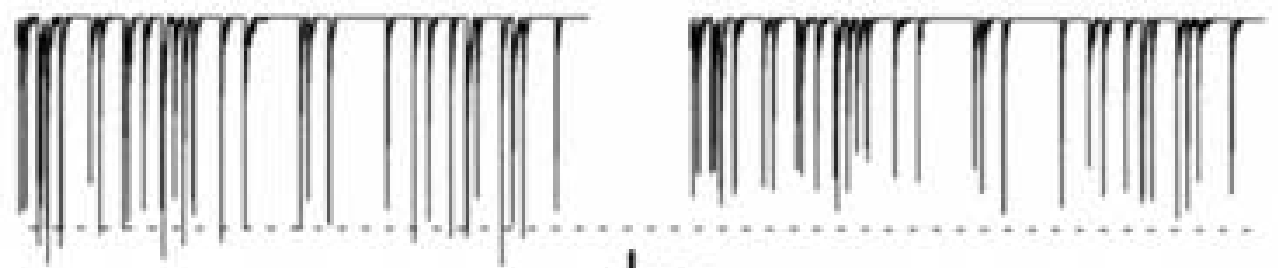

$\int_{1 \mathrm{~s}} 50 \mathrm{pA}$

$\mathrm{C}_{1}$

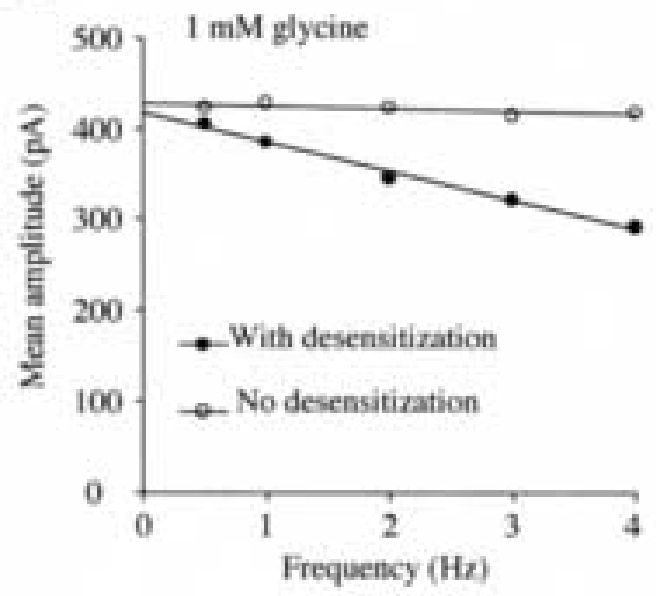

D1

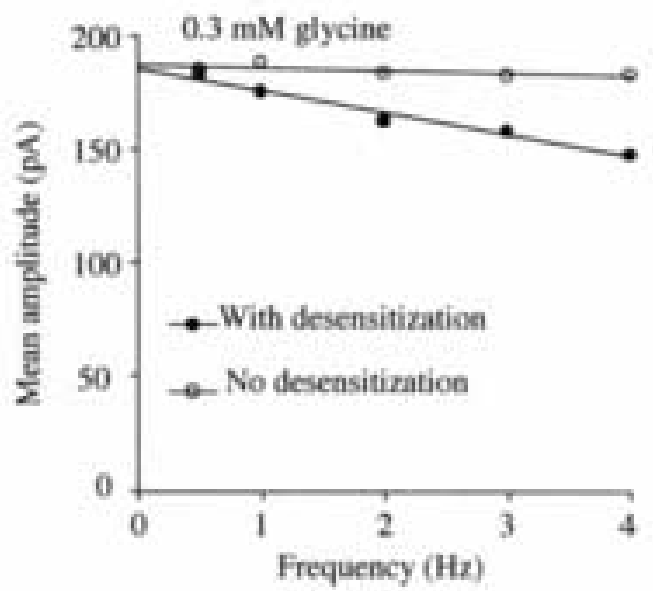

$\mathrm{C}_{2}$

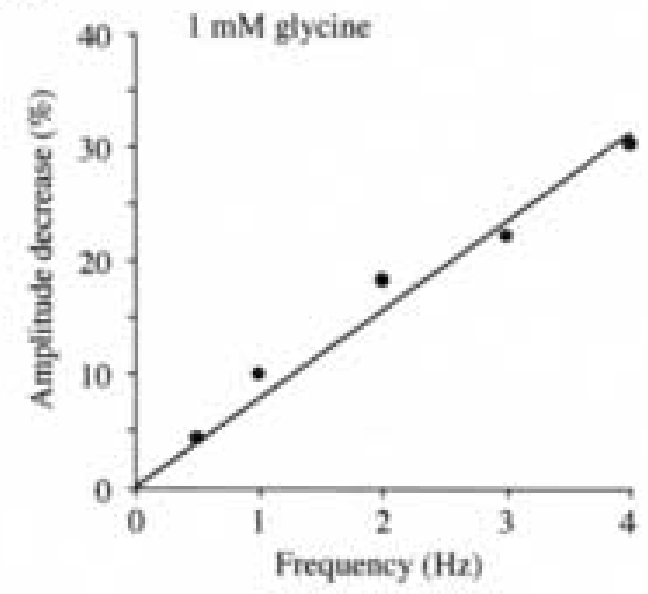

$\mathrm{D}_{2}$

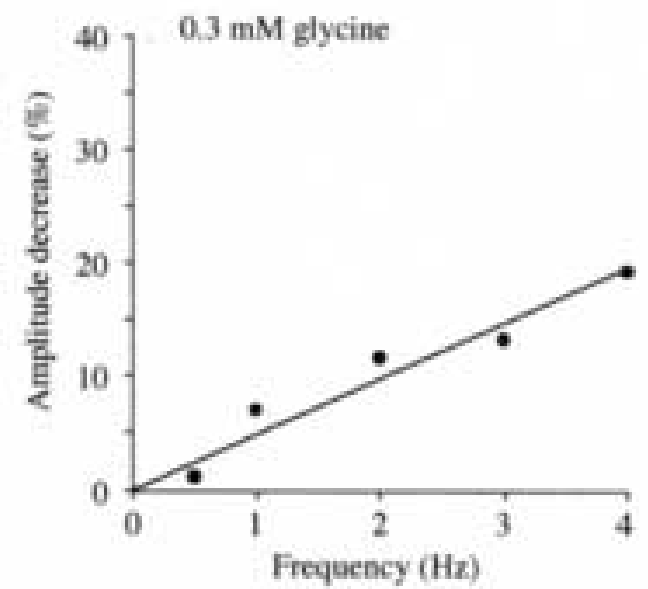

